OECD Education Working Papers No. 214

\author{
Attendance in early \\ childhood education \\ and care programmes \\ and academic proficiencies \\ at age 15
}

Jaime Balladares, Miloš Kankaraš 
DIRECTORATE FOR EDUCATION AND SKILLS

\section{Attendance in Early Childhood Education and Care Programmes and Academic Proficiencies at Age 15}

\section{OECD Education Working Paper No. 214}

By Jaime Balladares (Pontificia Universidad Católica de Chile) and Miloš Kankaraš (OECD)

\section{This working paper has been authorised by Andreas Schleicher, Director of the Directorate for} Education and Skills, OECD.

Michael Ward (michael.ward@oecd.org)

JT03457104 


\section{OECD EDUCATION WORKING PAPERS SERIES}

OECD Working Papers should not be reported as representing the official views of the OECD or of its member countries. The opinions expressed and arguments employed herein are those of the author(s).

Working Papers describe preliminary results or research in progress by the author(s) and are published to stimulate discussion on a broad range of issues on which the OECD works. Comments on Working Papers are welcome, and may be sent to the Directorate for Education and Skills, OECD, 2 rue André-Pascal, 75775 Paris Cedex 16, France.

This document, as well as any data and map included herein, are without prejudice to the status of or sovereignty over any territory, to the delimitation of international frontiers and boundaries and to the name of any territory, city or area.

The statistical data for Israel are supplied by and under the responsibility of the relevant Israeli authorities. The use of such data by the OECD is without prejudice to the status of the Golan Heights, East Jerusalem and Israeli settlements in the West Bank under the terms of international law.

You can copy, download or print OECD content for your own use, and you can include excerpts from OECD publications, databases and multimedia products in your own documents, presentations, blogs, websites and teaching materials, provided that suitable acknowledgement of OECD as source and copyright owner is given. All requests for public or commercial use and translation rights should be submitted to rights@oecd.org.

Comment on the series is welcome, and should be sent to edu.contact@oecd.org.

This working paper has been authorised by Andreas Schleicher, Director of the Directorate for Education and Skills, OECD.

www.oecd.org/edu/workingpapers

(C) OECD 2020 
Acknowledgements

Jaime Balladares acknowledges funding from the OECD Thomas J. Alexander fellowship programme for carrying out this work. 


\section{Abstract}

Early years are a critical period for skill development. In this sense, the Early Childhood Education and Care (ECEC) programmes have an important role in promoting children's learning during this period. This study aimed to explore the effectiveness of ECEC programmes by analysing the relationship between students' ECEC attendance and their later academic proficiency using PISA 2015 data. PISA results show that across the OECD countries, students who had attended ECEC tend to have higher scores in academic proficiencies at the age of 15 . However, these differences in academic proficiencies between those who attended ECEC versus those who did not attend are almost nil when students' socio-economic status (SES) is considered. This relationship reflects differential access to learning opportunities for children from deprived contexts. Furthermore, results show that entering ECEC programmes earlier than the typical time is associated with lower proficiencies at the age of 15 . Therefore, earlier entry to ECEC is not necessarily beneficial.

Learning benefits of ECEC provision vary considerably across PISA countries illustrating the importance of a country-specific policy context and the quality of their ECEC provision. The analyses of several quality indicators point out that the improved quality of ECEC programmes is associated with higher academic skills at later stages. These results highlight that mere attendance to ECEC programmes is not enough to ensure better academic performance. The quality of the educational provision, especially concerning those students from disadvantaged backgrounds, should be ensured.

\section{Résumé}

La petite enfance est une période critique pour le développement des compétences. Dans ce sens, les programmes pour l'Éducation et l'Accueil des Jeunes Enfants (EAJE) jouent un rôle important en favorisant l'apprentissage de l'enfant durant cette période. Cette étude vise à examiner l'efficacité des programmes d'EAJE en analysant la relation entre la participation des élèves dans ces programmes et leurs performance scolaires, utilisant les données PISA 2015. Les résultats de PISA montrent qu'à travers les pays de l'OCDE, les élèves ayant suivi un programme EAJE ont tendance à avoir des scores et performances scolaires plus élevés, à l'âge de 15 ans. Toutefois, ces différences dans les performances scolaires entre ceux ayant suivi un programme d'EAJE et ceux qui n'en ont pas suivi sont presque nulles lorsque l'on prend en considération les compétences sociales et émotionnelles des élèves. Cette relation souligne les disparités concernant l'accès aux opportunités d'apprentissage pour les enfants venant de milieux défavorisés. De plus, les résultats montrent qu'une participation précoce dans un programme d'EAJE est parfois associée à des performances plus basses à l'âge de 15 ans. Ainsi, la participation précoce dans un programme d'EAJE n'est pas nécessairement bénéfique.

Les bénéfices d'apprentissage des programmes d'EAJE varient considérablement entre les pays de PISA, ce qui illustre l'importance du contexte politique spécifique au pays et de la qualité des programmes d'EAJE. Les analyses de nombreux indicateurs de qualité démontrent qu'un programme d'EAJE de meilleure qualité est associé à des compétences scolaires plus élevés, à posteriori. Ces résultats soulignent que la seule participation aux programmes d'EAJE ne suffit pas à assurer une meilleure performance scolaire. La qualité du régime éducationnel, surtout concernant les élèves venant de milieux défavorisés, doit être assurée. 


\section{Table of contents}

$\begin{array}{ll}\text { Abstract } & 4\end{array}$

Résumé 4

1. Introduction 7

2. Importance of early child development 9

3. Variation in the starting age of ECEC by socio-economic background 11

4. Association between duration of ECEC attendance and later academic proficiency

6. Conclusions

\section{Table}

Table A A.1. Typical age of entry to early childhood education and care (ECEC) by country and economies according PISA 2015

\section{Figures}

Figure 1. ECEC attendance rates

Figure 2. Age of entry by low and high socio-economic status (SES) groups

Figure 3. Percentage of low attendees' students by socio-economic status (SES) quartiles

Figure 4. Age at which students started early childhood education and care (ECEC)

Figure 5. Relationship between duration of ECEC attendance and proficiencies at age 15

Figure 6. Percentage of score gains by typical age (and one year earlier/later)

Figure 7. Score gains between low attendees and attendees at typical age (PISA Reading test)

Figure 8. Relationships between ECEC attendance and science proficiency before and after accounting for socio-economic background 
Figure 10. Relationship between ECEC attendance and science proficiency across countries Figure 11. Differences in proficiency scores depending on staff training

Figure 12. Differences in students' science proficiency and type of funding of their early childhood education and care (ECEC) institutions

Figure 13. Differences in duration of ECEC attendance, by school's characteristics

Figure 14. Relationship between intensity of ECEC attendance and proficiency at age 15

Figure 15. Parental reason for child's attendance of different types of early childhood education and care (ECEC) programmes and students' science proficiency

Figure A A.1. Age of entry without considering 'typical age' by country

\section{Box}

Box 1. ECEC Terminology 


\section{Introduction}

The Programme for International Student Assessment (PISA) is a study administered by the Organisation for Economic Co-operation and Development (OECD) with their member and non-member countries and economies that evaluates educational systems by measuring 15-year-old school students' performance on mathematics, science and reading. The first edition of PISA started in 2000 and it has been repeated in cycles every three years since. Policy makers around the world use PISA findings to gauge the knowledge and skills of students in their own country/economy in comparison with those in other participating countries/economies, establishing benchmarks for improvements in the education provided and/or in learning outcomes, and understanding the relative strengths and weaknesses of their own education systems.

Attending early childhood education and care (ECEC) can be considered one of the factors that explains later differences in students' proficiency scores both within and across countries (see Box 1 for some explanations regarding ECEC terminology used in this paper). When children enter primary school, they already differ in their language, early literacy and numeracy skills, as well as their social and emotional skills. Those differences are often maintained or amplified later in life (Berlinski, Galiani and Gertler, $2009_{[1]}$; Entwisle, Alexander and Olson, 1997 ${ }_{[2]}$; Mistry et al., 2010 $\left.0_{[3]}\right)$. ECEC programmes are thus seen as one avenue to promote early development and raise achievement levels of all children, especially of those from disadvantaged backgrounds. Investing in early education programmes can be considered an effective policy investment with a myriad of long-term benefits (Heckman, 2006 $[4]]$. The importance of ECEC participation has been analysed in several OECD (OECD, 2011 $1_{[5]}$; OECD, 2013 $3_{[6]}$; OECD, 2014 ${ }_{[7]}$; OECD, $2015_{[8]}$ ) countries. The participation is important, but the ECEC quality is complementary. It has been established that higher-quality programs in ECEC tend to produce larger effects in areas such as vocabulary and math (Yoshikawa, Weiland and Brooks-Gunn, 2016 ${ }_{[9]}$ ).

To examine possible effects of this early learning provision on later academic outcomes of these children, PISA included questions about attendance in ECEC, starting from the second round of PISA in 2003. In PISA 2015, a much broader set of questions about ECEC provisions were asked not only to students but also to parents. Students were asked about the starting year of their ECEC attendance (rather than directly about ECEC duration) and starting year of their primary school. Based on this information it was then possible to deduct the duration of their ECEC attendance, and the 'typical age' of entry at country level, which will be discussed in the current document. In addition, students' parents were also asked a wide set of questions on attendance in different types of ECEC settings, reasons for attending, types of ECEC centres, etc.

The results of this report show that a large proportion of children have attended ECEC; however, the fact of attending is invariably associated with the student's socio-economic status. The data collected from PISA 2015 showed that children from low socio-economic contexts are significantly more likely not to attend ECEC compared to their peers from high socio-economic status. In addition, those children who grew up in more disadvantaged contexts tend to attend ECEC later compared to their peers from high socio-economic status. This report introduces the idea of "typical age of entry" to explicit the age in which children more often start to attend to ECEC at country-level. This typical age of entry allows making fairer comparisons among children from a same cohort. The results show, in almost all countries and economies participating in PISA 2015, significantly better results for those children who attend at the typical age of entry in each country/economy compared to those children who attend solely one year to ECEC or those who reported not having attended. The report emphasises the importance of quality in ECEC, factors such as 
staff-to-child ratio, staff training, management and funding type, and the intensity of ECEC, which undoubtedly must be included in the design of ECEC policies.

It is, of course, important to note that not all of the observed performance differences at age 15 may be due to what happened before entry into schooling. The fact that the performance advantage of attending ECEC washes out after accounting for economic and social background may be as much a function of what happened in school than the prevalence and quality of ECEC.

\section{Box 1. ECEC Terminology}

According to the OECD $\left(2017_{[10]}\right)$, early childhood education and care (ECEC) is defined as "regulated arrangements that provide education and care for children from birth to compulsory primary school age in integrated systems, or from birth to preprimary education in split systems".

The focus of the internationally comparable statistics, International Standard Classification of Education level 0 (ISCED level 0), is much narrower. ISCED level 0 refers to early childhood programmes that have an intentional education component. To be reported in ISCED level 0, a programme must (OECD, European Union and UNESCO-UIS, 2015 $[11]$ ):

1. have adequate intentional educational properties

2. be institutionalised (usually school-based or otherwise institutionalised for a group of children)

3. have an intensity of at least two hours per day of educational activities and a duration of at least 100 days a year

4. have a regulatory framework recognised by the relevant national authorities (e.g. curriculum)

5. have trained or accredited staff (e.g. requirement of pedagogical qualifications for educators).

There are two categories of ISCED level 0 programmes, which are classified depending on age and the level of complexity of the educational content:

- ISCED level 1 refers to early childhood educational development programmes, typically aimed at children under age 3 . The learning environment is visually stimulating, and the language is rich and fosters self-expression, with an emphasis on language acquisition and the use of language for meaningful communication. There are opportunities for active play so that children can exercise their co-ordination and motor skills under supervision and in interaction with staff.

- ISCED level 2 refers to pre-primary education programmes, aimed at children in the years immediately prior to starting compulsory schooling, typically aged between age 3 and age 5 . Through interaction with peers and educators, children improve their use of language and their social skills, start to develop logical and reasoning skills, and talk through their thought processes. They are also introduced to alphabetical and mathematical concepts, understanding and use of language, and are encouraged to explore their surrounding world and environment. Supervised gross motor activities (i.e. physical exercise through games and other activities) and play-based activities can be used as learning 
opportunities to promote social interactions with peers and to develop skills, autonomy and school readiness.

Currently, at least four strands of research support the relevance of applying a broader definition of ECEC rather than focusing on ISCED level 0 alone: brain research, studies on domain-specific development and support, evaluation studies of model programmes, and longitudinal large-scale studies all rely on the broader definition of ECEC. Thus, conclusions about the importance of early childcare should be drawn with ECEC and not with ISCED level 0 in mind.

In this paper, we use the term ECEC to refer to ISCED level 0. The other registered ECEC services are considered an integral part of countries' ECEC provision but do not comply with all the ISCED level 0 criteria to be considered as educational programmes (e.g. crèches in France or amas in Portugal are not taken into account). Therefore, we urge readers to notice the wider framework of programmes and settings that ECEC includes and that are not covered in the operational definitions of early childhood education and care used in PISA (For more details, see Indicator B2 and Table B2.4 of the OECD's Education at a Glance 2018 $)$.

\section{Importance of early child development}

Children learn at an exceptional pace during their early years (Shuey and Kankaraš, $\left.2018_{[12]}\right)$. In their early years, children boost language, literacy, math and prosocial skills in a very limited period (Yoshikawa, Weiland and Brooks-Gunn, 2016 $6_{[9]}$ ). Therefore, it is important to ensure that they are provided with rich and stimulating environments for their skills full development. Although families have the strongest influence in promoting children's early learning, ECEC programmes also have strong potential to support young children. Attending high-quality ECEC has proved to bring cognitive, emotional, and social benefits for children (Fuller et al., 2017[13]; Shuey and Kankaraš, 2018 ${ }_{[12]}$ ). Specifically, promoting high quality programmes in ECEC settings has shown to be associated with larger gains in children's skills (Yoshikawa, Weiland and Brooks-Gunn, 2016 [9] ). The effect of ECEC is particularly important for those children coming from deprived contexts, given the learning opportunities that they can acquire in those critical years (Pungello et al., $2010_{[14]}$; Reynolds et al., 2011 $1_{[15]}$; Duncan and Magnuson, 2013 ${ }_{[16]}$; Yoshikawa et al., $\left.2013_{[17]}\right)$. Indeed, it has been stated that difficulties in emergent literacy in children from low socio-economic status can be reduced or ameliorated by the effect of attending ECEC (Barnett, 2001 $\left.{ }_{[18]}\right)$. From a policy perspective, investing in developing high quality provision at this level brings later substantial economical returns (Temple and Reynolds, $\left.2007_{[19]}\right)$.

Countries and economies have developed efforts to increase the provision coverage in this level. For example, Chile, the Czech Republic, Denmark, Estonia, Italy, Poland, the Russian Federation and the United States have designed and administered several policies to increase the participation of children in ECEC from the early years. However, although the majority of children in OECD countries nowadays attend some form of ECEC programmes, they still differ significantly in two important respects. First, the age of entry into ECEC varies among them, leading to considerable differences in the average duration

\footnotetext{
${ }^{1}$ https://doi.org/10.1787/eag-2018-en
} 
10 | EDU/WKP(2020)2

of ECEC attendance across the OECD countries (Figure 2). Secondly, the children's socio-economic status seems to play an important role to explain the participation in ECEC. Considering both the age of entry and the socio-economic status of the participants could help to design better policies at this level. Secondly, the quality of ECEC provisions varies considerably, especially regarding their educational element, and these differences are also leading to different effectiveness of ECEC programmes across OECD countries (Shuey and Kankaraš, 2018 $8_{[12]}$. Figure 1 shows the ECEC attendance rates in the countries and economies participating in PISA 2015.

Figure 1. ECEC attendance rates

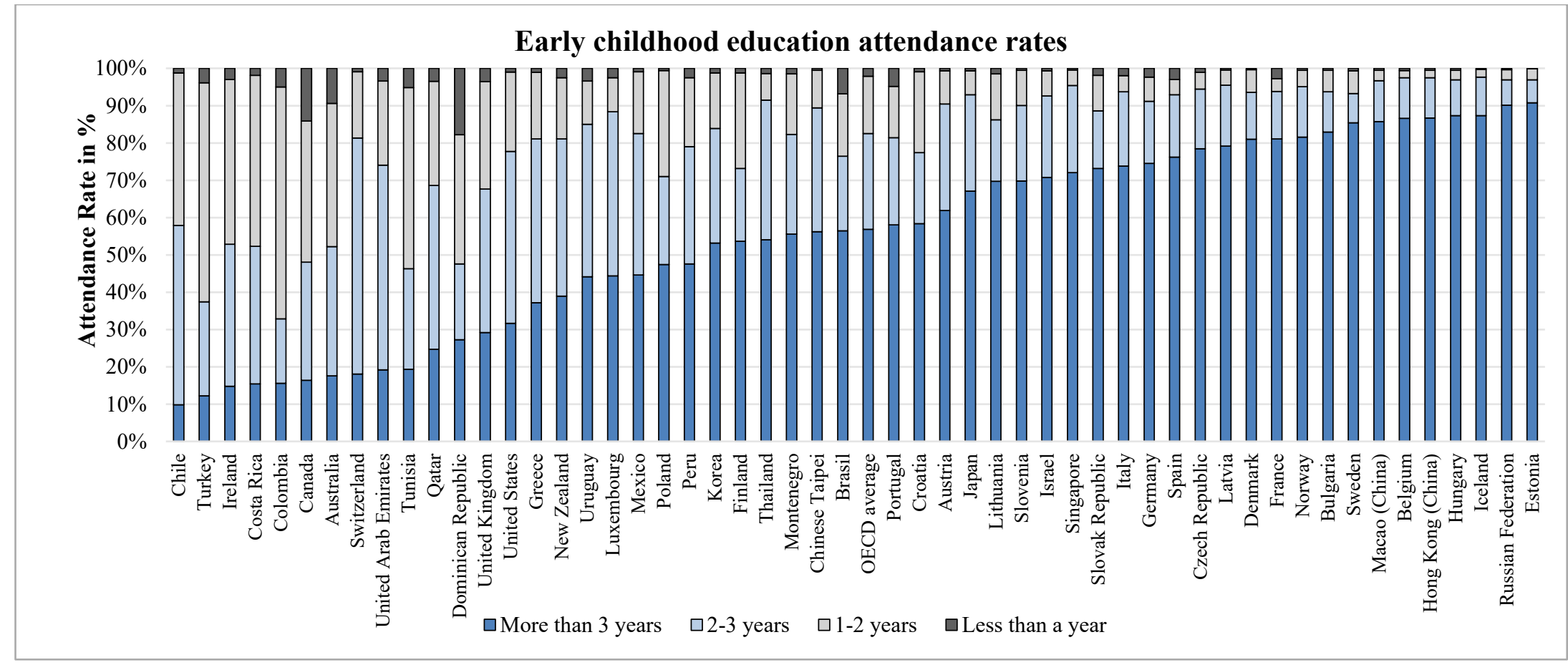

1. B-S-J-G (China) refers to the four PISA-participating Chinese provinces of Beijing, Shanghai, Jiangsu and Guangdong. Source: (OECD, 2015[20]), PISA 2015 Database (accessed 15 November 2019). 
In addition to the policies that promote the adequate skills development through offering ECEC to their children, the socio-economic status (SES) can be considered an unavoidable factor that influences not only the development, but also the ECEC participation. Several studies have shown that SES is one of the most important factors influencing students' later educational outcomes (Roberts, Jurgens and Burchina, 2005 [21]; Noble, Farah and McCandliss, 2006 $6_{[22]}$; Weigel, Martin and Bennet, 2006 ${ }_{[23]}$. It has been characterised as a multi-dimensional factor, which evaluates the nature, timing, and persistence of poverty in the population (Brooks-Gunn and Duncan, $7_{[24]}$ ). Even though there is no agreement about the way to evaluate SES, most authors agree to include some quantification of, at least, parental education, family income, and occupational status. PISA test captures the student's socio-economic status through the Economic, Social and Cultural Status (ESCS) index. This measure includes a range of indicators such as parental education (PARED), highest parental occupation (HISEI), and home possessions (HOMEPOS), as well as a measure of cultural capital expressed by the number of books at home. These three components are transformed into a continuous variable, and represent the dimensions often reported by the literature associated to later academic achievement ${ }^{2}$.

The impact of socio-economic status on educational outcomes has been considered one of the main challenges to reach equity in education (Buckingham, Beaman and Wheldall, $\left.2013_{[25]}\right)$. This is, to provide for all students a good educational quality regardless family background, student's socio-economic status and gender (OECD, 2012 $\left.{ }_{[26]}\right)$. For example, the studies about literacy and SES show that children from low SES perform worse in standardised tests than their peers with high SES (Arnold and Doctoroff, 2003 ${ }_{[27]}$; OECD, $2013_{[6]}$; Aikens and Barbarin, 2008 ${ }_{[28]}$ ). Differences in language performance associated with socio-economic status might be evident already at 18 months (Fernald, Marchman and Weisleder, 2013 ${ }_{[29]}$. Evidence also indicates that high quality learning opportunities in the early years increase future earnings and reduce later life inequality (Ruhm and Waldfogel, 2012[30]; Shuey and Kankaraš, 2018 $\left.{ }_{[12]}\right)$.

The effect of SES on academic outcomes is not direct but it is mediated by several factors related to the features of the environment where a child develops. These factors consider aspects such as 'Home literacy environment', which includes those learning-related interactions, resources and attitudes that children experience at home (Hamilton et al., $2016_{[31]}$ ), and ECEC features in terms of attendance and quality of teaching. Evidence indicates that children from deprived contexts receive less learning opportunities at home than their peers from high socio-economic backgrounds. For example, it has been reported that in low socio-economic contexts, parents are less likely to purchase learning and reading materials for their children, less likely to take children to cultural events, and less likely to regulate the time children spend watching TV (Bradley et al., 2001 [32]). As a result, children growing up in a more disadvantaged environment acquire language skills slower than their peers from higher socio-economic backgrounds, delaying the processes of reading acquisition (Whitehurst and Lonigan, 1998 $[33]$ ). On the other hand, the effect of attending high quality ECEC is associated with positive and larger effect on different areas such as language, math, and social skills (Yoshikawa, Weiland and Brooks-Gunn, 2016[9]).

\section{Variation in the starting age of ECEC by socio-economic background}

In PISA 2015, students were asked about the age in which they entered at ECEC. Eight different options were presented to students: 1 year and younger $(18687-4.3 \%), 2$ years

\footnotetext{
${ }^{2}$ In this report, ESCS scale has been transformed into four equivalent socio-economic quartiles according each participant country.
} 
$(51502-12.0 \%), 3$ years $(132518-30.8 \%), 4$ years $(77599-18.1 \%), 5$ years $(52407-$ $12.2 \%), 6$ years or older (21 $174-4.9 \%)$, I did not attend (20 131-4.7\%), I did not remember $(55889-13.0 \%)$. The results show that a large proportion of the students reported having attended ECEC at least one year $(82.3 \%)$, with most students entering their ECEC programmes at age $3(30.82 \%)$. Only $4.7 \%$ of the students reported not having attended to this level, and a similar proportion reported having attended for one year (4.9\%). In addition, $13.0 \%$ of the students selected the option 'Do not remember'. In Figure 1 both the age of entry and the student's socio-economic status (SES) have been included. SES is represented by comparing the low and top quartiles of PISA's ESCS scale. In this report, those children that attended ECEC from 6-years old and those who report not having attended ECEC have been labelled in the category 'low attendance'. The comparison between these children is important in order to highlight the differences between those children coming from low and high SES. In addition, these groups facilitate analysis of the differences associated with SES in each PISA country and economy (Figure 2).

\section{Figure 2. Age of entry by low and high socio-economic status (SES) groups}

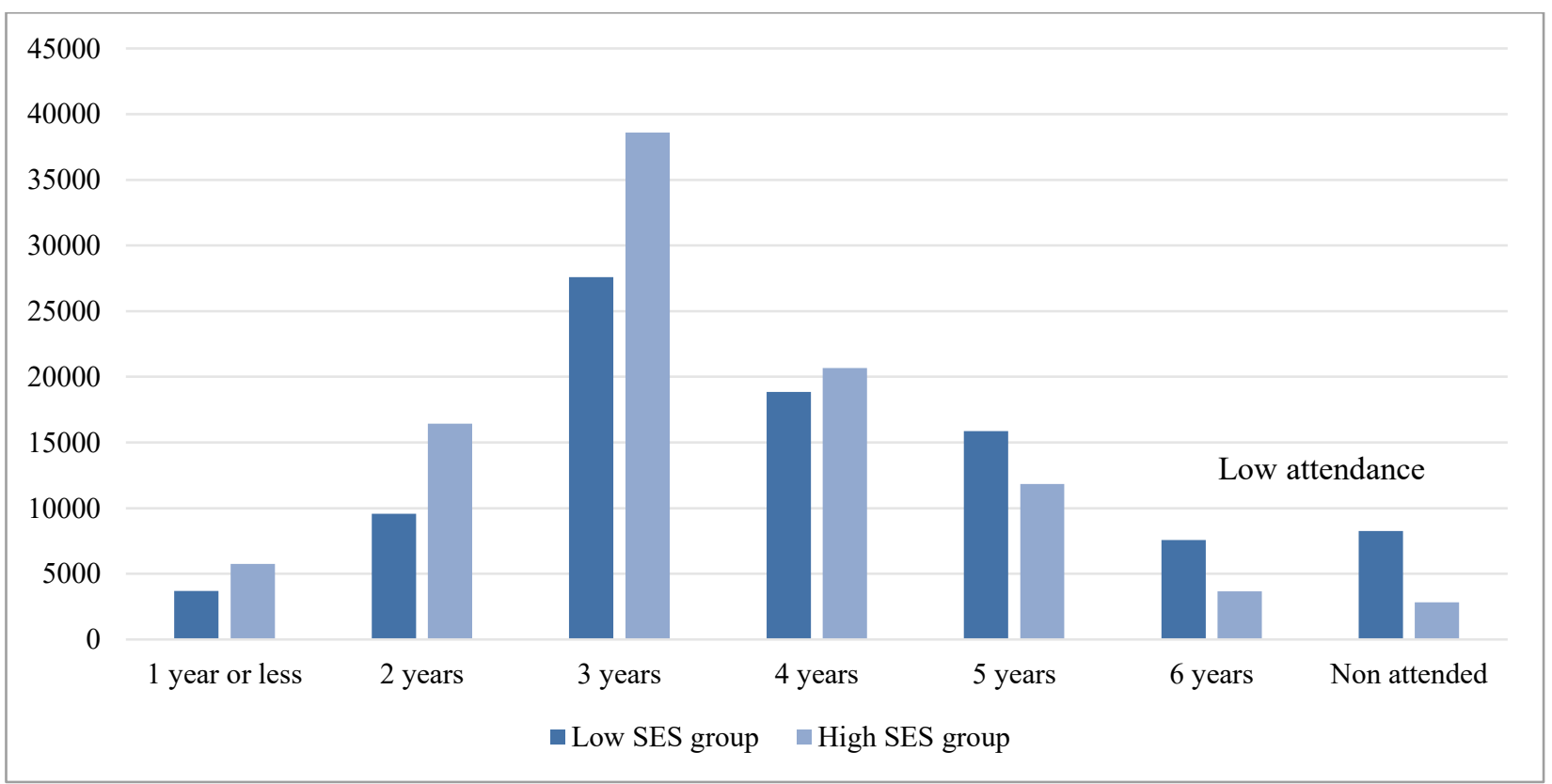

Source: (OECD, 2015[20]), PISA 2015 Database (accessed 15 November 2019).

The results show significant associations between children's socio-economic status and the age of entry in ECEC $[\chi 2(21)=9.8 \mathrm{e}+03, \mathrm{p}<0.001]$. Figure 3 shows that children from high SES attend ECEC earlier than their peers from low SES. In addition, the proportion of children attending ECEC later or not attending is significantly higher in the low SES group than their peers from high SES. Students from low SES group were almost three times more likely to report that they did not attend ECEC programmes compared to students with high SES. Figure 3 shows that this inequality of attendance across students with different SES background appears commonly among all countries and economies participating in PISA 2015. 
Figure 3. Percentage of low attendees' students by socio-economic status (SES) quartiles

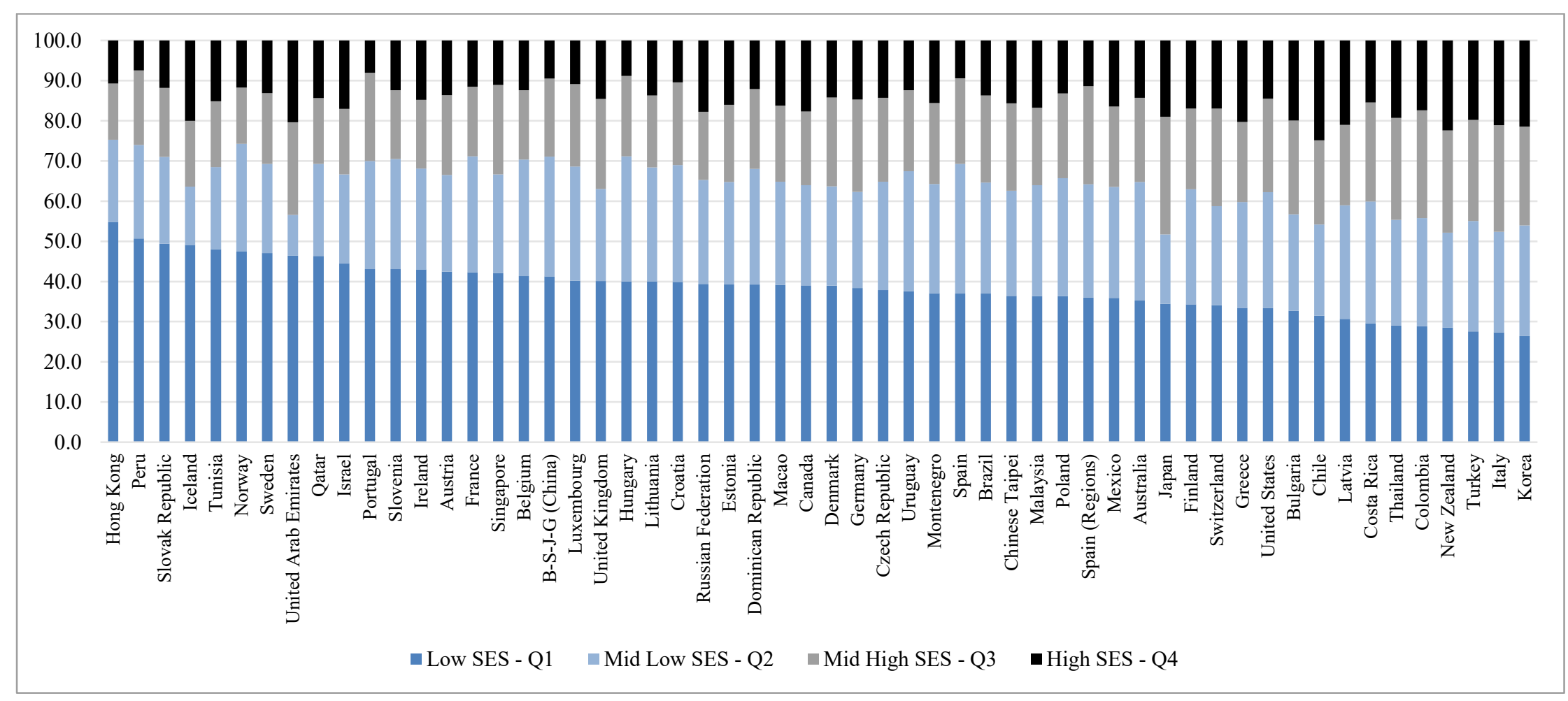

Source: (OECD, 2015[20]), PISA 2015 Database (accessed 15 November 2019).

Differences expressed in Figure 2 are particularly significant in the case of Hong-Kong and Peru, where more than a half of the low attendees' students belong to the low SES quartile. In sum, the fact of attending ECEC and the age of entry is related to the student's SES. Children from low SES tend to be less likely to attend or attend later than their peers from high SES. Thus, given that one of the main policy objectives of the ECEC programmes is to improve equity and allow disadvantaged children equal opportunities, there is a clear space for improvement for countries as a way to promote higher participation of children from disadvantaged backgrounds. 


\section{Association between duration of ECEC attendance and later academic proficiency}

\subsection{Is starting ECEC programmes early beneficial for children?}

Figure 4 shows the age of entry across PISA participants (countries and economies). Across OECD countries, most children begin ECEC at the age of three (see Figure 4).

Figure 4. Age at which students started early childhood education and care (ECEC)

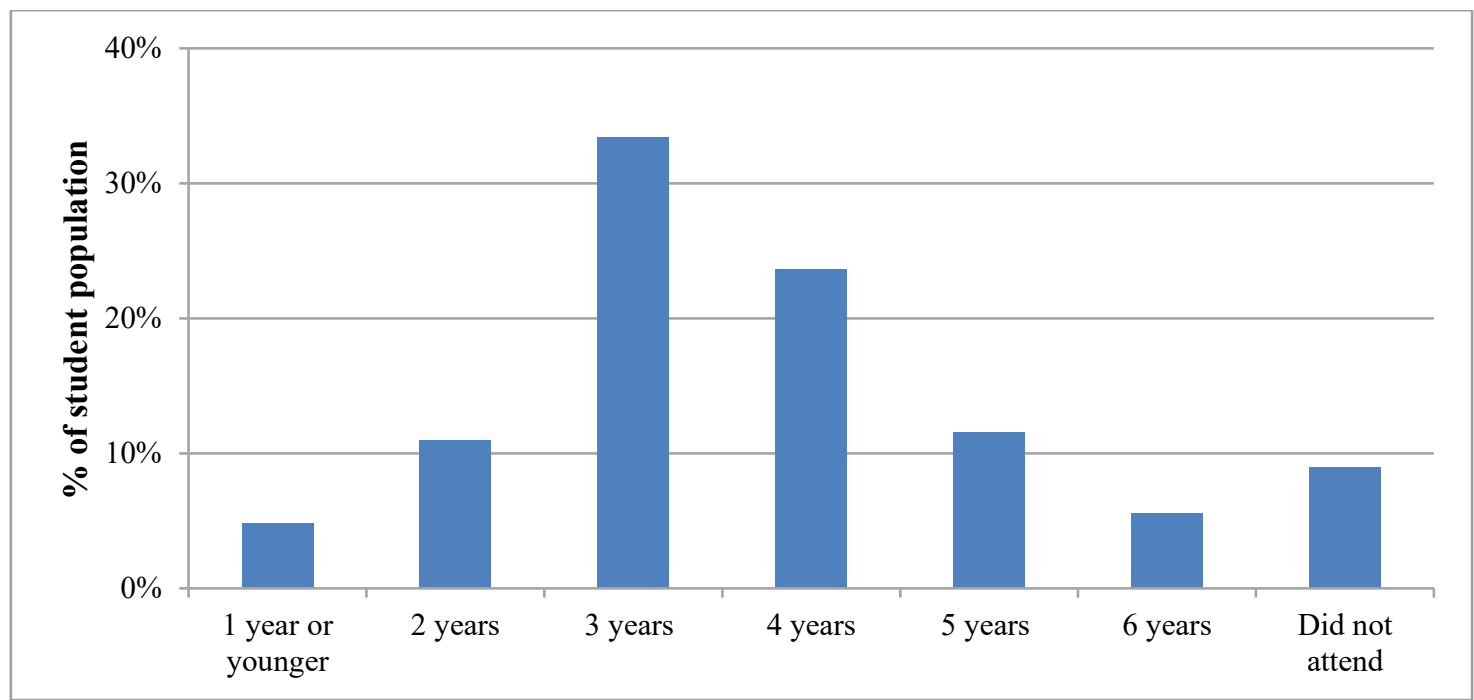

Source: (OECD, 2015[20]), PISA 2015 Database (accessed 15 November 2019).

Despite some evidence that ECEC can be beneficial for children, many of these findings come from studies of three- and four-year-olds. Positive influence of ECEC programmes on younger children is less convincing, particularly related to the emergence of behaviour problems (NICHD Early Child Care Research Network and Duncan, 2003 [34]; NICHD Early Child Care Research Network, $2005_{[35]}$; NICHD Early Child Care Research Network, $\left.2006_{[36]}\right)$.

Based on data from PISA 2015, duration of ECEC experience appears to be associated to students' academic achievement at age 15 in a non-linear way. Across OECD countries, the average time spent in ECEC is three years. The relationship between the average time spent in ECEC settings and later students' proficiency is shown in Figure 5. We can see that this relationship is not linear, but rather curvilinear. It shows a roughly linear increase in proficiencies with longer duration until an average duration of 4 years. Actual reversal effects and a slight decrease in proficiencies follow further increase in duration. These findings might indicate that children who are starting at ECEC participation at a very early age will not necessary benefit from this early participation (Figure 5). On the other hand, the results again confirm that children starting around age 3 have much higher proficiencies than those starting later, at ages 5 or 6 . 
Figure 5. Relationship between duration of ECEC attendance and proficiencies at age 15

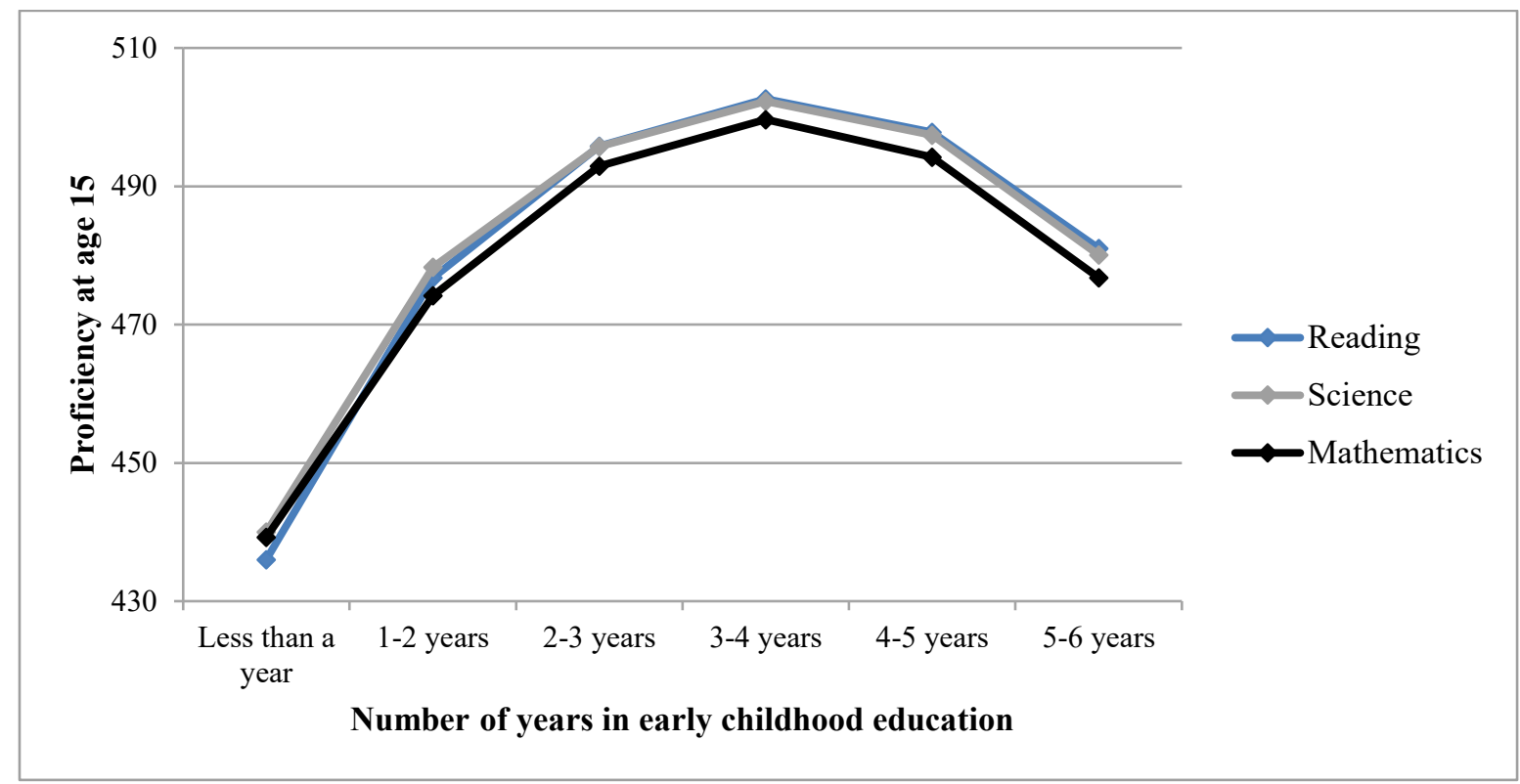

Source: (OECD, 2015[20]), PISA 2015 Database (accessed 15 November 2019).

\subsubsection{Typical age of entry}

It is important to note that presented aggregate-level data conceal important differences across countries. In several countries that have a typical starting age of ECEC earlier than others do, at age 2 (in most countries it is at age 3), this trend is somewhat different. For example, in some countries the higher proportion of children enters at 2 years-old (e.g. Belgium, Iceland, Norway and Sweden), while in other countries the age of entry is typically 5 (e.g. Colombia, Costa Rica, Dominican Republic, Chinese Taipei, Malaysia, Tunisia and Turkey). In countries with earlier typical age of entry, those students that entered ECEC already at age 2 tend to have highest scores in Science proficiency at age 15. These differences in the age of entry can be associated with later academic outcomes, in the sense of the exposure to ECEC. Children who enter earlier to ECEC are exposed to a large range of opportunities to develop their skills and these factors invariably impact on the way in which children boost their performance in areas such as language, math, and prosocial behaviours. The variation in the age of entry among countries and economies must be examined by considering wider ECEC and country context. In other words, general setup of the ECEC system in a country and especially its content and quality will lead to varying results with the same duration of ECEC experience (Kankaraš, 2017 [37]).

These differences among countries and economies in the age of entry to ECEC are related to the available services that they offer. The variation in the ECEC offer is associated with the responsible institutions. Thus, in those cases in which ECEC services are managed under one (leading) authority (at the national and/or regional level), e.g. Ministry of Education, Ministry of Social Welfare or another authority, often the ECEC enrolment (e.g. ISCED level 1) starts earlier than those cases in which the governance is shared between different ministries (e.g. in ISCED level 2). Therefore, presenting aggregate-level data allows fairer comparisons by comparing those different models in which ECEC is offered, because it includes a peer comparison at country level.

In order to incorporate this important information in the examination of the association between duration of ECEC attendance and later academic proficiencies, the following 
analyses will follow the principle of typical age of entry. The typical starting age of ECEC has been calculated for each participant country considering the largest proportion of students attending ECEC at a certain age. For example, in Denmark, almost 50\% of students reported in the PISA 2015 test as having started ECEC at age 3. Whereas in Norway, the majority of students entered ECEC at age 2. Therefore, ages 3 and 2, respectively, were defined as the typical age of entry to ECEC. Additionally, two more categories have been added: one year earlier (in this example, age 1 or younger for Norway and age 2 in Denmark) and one year later (in this example, age 3 for Norway and age 4 for Denmark). The first category refers to students who had a lower ECEC age of attendance in comparison to most students; the second category refers to those who entered into ECEC at a later age in comparison to most students. Low attendance and typical ages for each participant country are summarised in 0 .

Figure 6 shows a summary of the score gains between those low attendees' students, who reported not having attended or attended less than one year to ECEC, versus those who attended at typical age in each of the cognitive tests: PISA Reading, Math, and Science.

\section{Figure 6. Percentage of score gains by typical age (and one year earlier/later)}

Comparisons on PISA 2015 Reading, Math, and Science outcomes

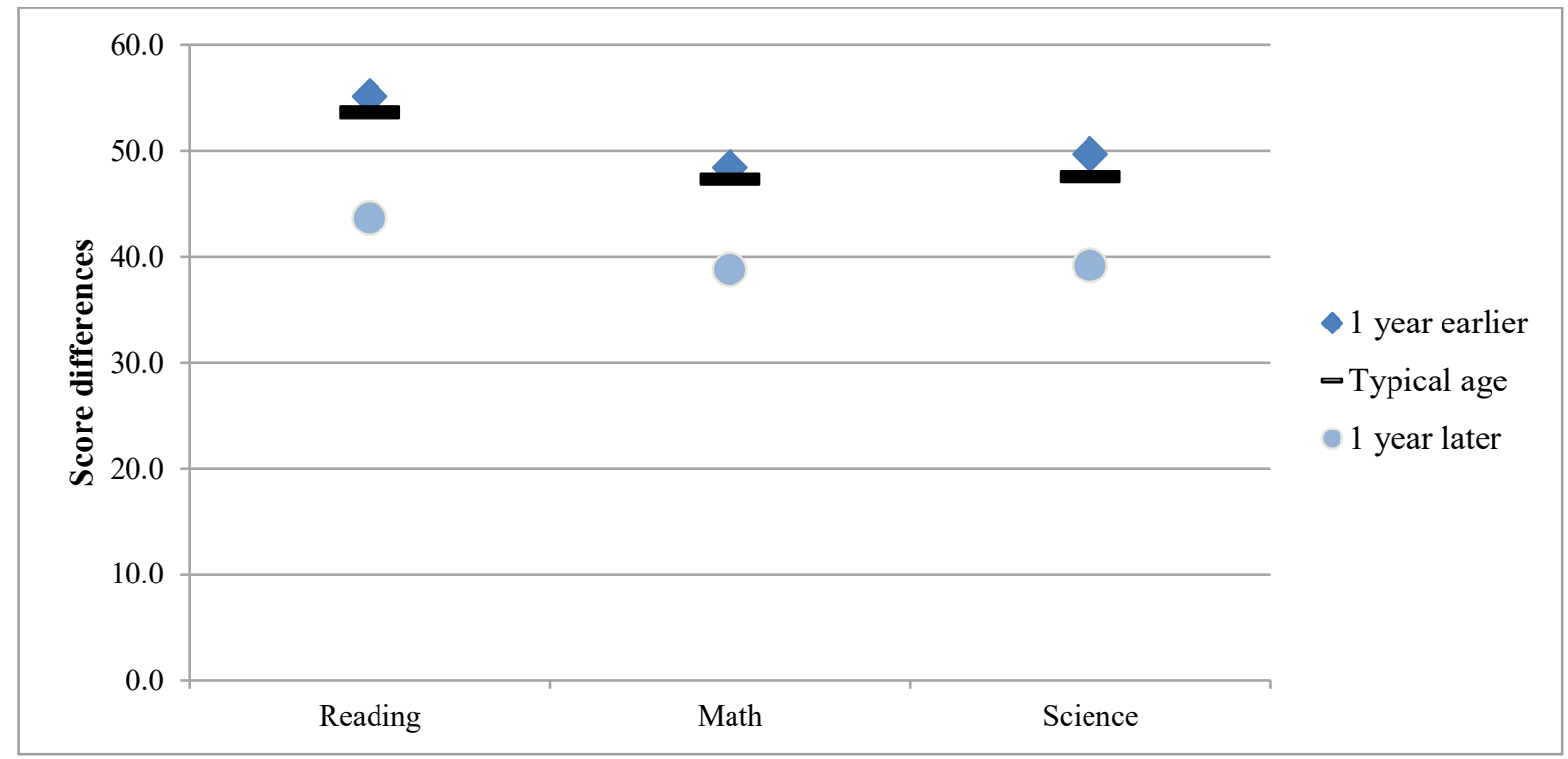

Note: Reference group is the low attendance group (this is those students who reported not having attended ECEC or having attended for less than one year). Red line, blue diamond, and green circle represent the score gains by the typical age group and one year (earlier/later), respectively.

Source: (OECD, 2015[20]), PISA 2015 Database (accessed 15 November 2019).

The results show that on average, those students who attended ECEC at typical age, reached 55.1 points more than their peers who started at a later age in the Reading test. These differences are quite similar compared to those found in Math (48.4 points), and Science outcomes (49.7). The pattern is relatively equal in the case of those children who reported having attended one year earlier than their peers who started at typical age (Reading [53.6 points]; Math [47.3]; Science [47.5]). In the case of those children who started one year later than the typical age, the differences are still large compared to those low attendees' students, but slightly lower compared to the scores reached for those who reported having attended ECEC at typical age (Reading [43.6 points]; Math [38.7]; Science [39.1]). 


\subsection{Low attendance and typical age in PISA outcomes by country}

In the following Figures, several comparisons between the mean scores reached by those students who attended ECEC at typical ages in each country and those who did not attend are presented. These results are presented at country level, and they include the scores of those students who entered one year earlier and one year later than the typical age for each country. Figure 7 presents the results for the PISA 2015 Reading outcomes, and similar patterns can be found in the Math and Science tests.

Figure 7. Score gains between low attendees and attendees at typical age (PISA Reading test)

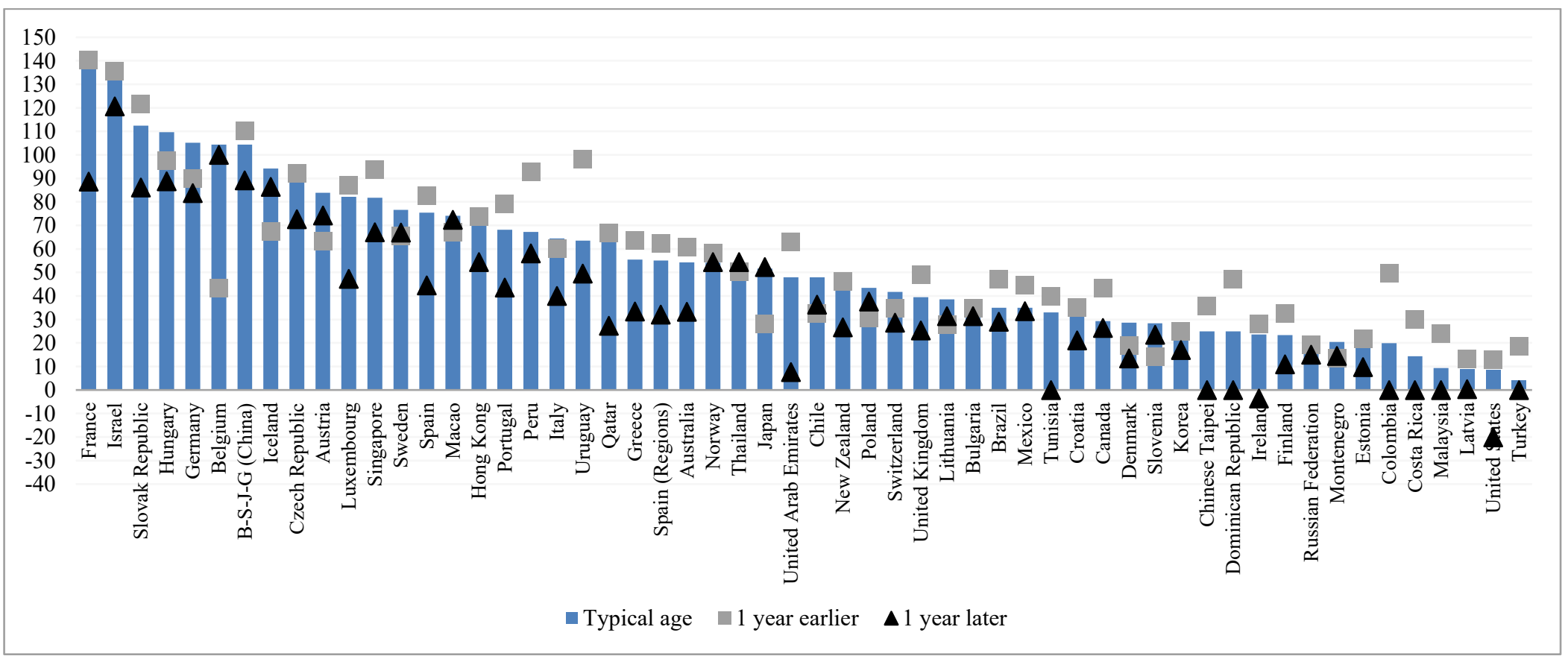

Notes: 1 . Grey colours represent no-significant differences between low attendees and attendees at typical age.

2. B-S-J-G (China) refers to the four PISA-participating Chinese provinces of Beijing, Shanghai, Jiangsu and Guangdong. Source: (OECD, 2015[20]), PISA 2015 Database (accessed 15 November 2019). 
In Figure 7, the results show that for all countries (except Latvia, the United States and Turkey) significant differences in terms of score gains were found for those students who attended ECEC at typical ages compared to those peers who started at a later age. In seven countries, this discrepancy appears for more than 100 points (B-S-J-G [China] [104.3], Belgium [104.4], Germany [105.2], Hungary [109.7], Slovak Republic [112.5], Israel [136.1], and France [136.8]). In 52 out of 56 countries and economies, significant differences were found in favour of those students who attended ECEC one year earlier than typical age compared to those students that attended one year later than typical age.

\subsection{Is the relationship of ECEC attendance and academic proficiency moderated by students' socio-economic status?}

Given that one of the primary policy objectives of ECEC programmes is to reduce the effects of existing socio-economic inequities on students' school achievement, it is important to examine how ECEC attendance's relationship with academic achievement varied across children coming from different SES backgrounds. Figure 8 shows that the association between the number of years in ECEC and children's science proficiency, in relation to children who did not attend ECEC, looks quite impressive when family SES is not included in the model. However, although attendance of ECEC (relative to not attending ECEC) is still associated with greater science proficiency at age 15 after accounting for family SES, it is so to a much lesser degree. The one exception to this finding is that attending less than one year of ECEC appears to be detrimental for later science proficiency, whether or not family SES is accounted for; however, fewer than $2 \%$ of students across OECD countries experienced this low level of ECEC exposure. These results indicate that ECEC programmes are not ameliorating existing socio-economic disparities in academic performance between children. In other words, the effects of socio-economic disparities among children are largely still preserved despite varying amounts of ECEC experience. 
Figure 8. Relationships between ECEC attendance and science proficiency before and after accounting for socio-economic background

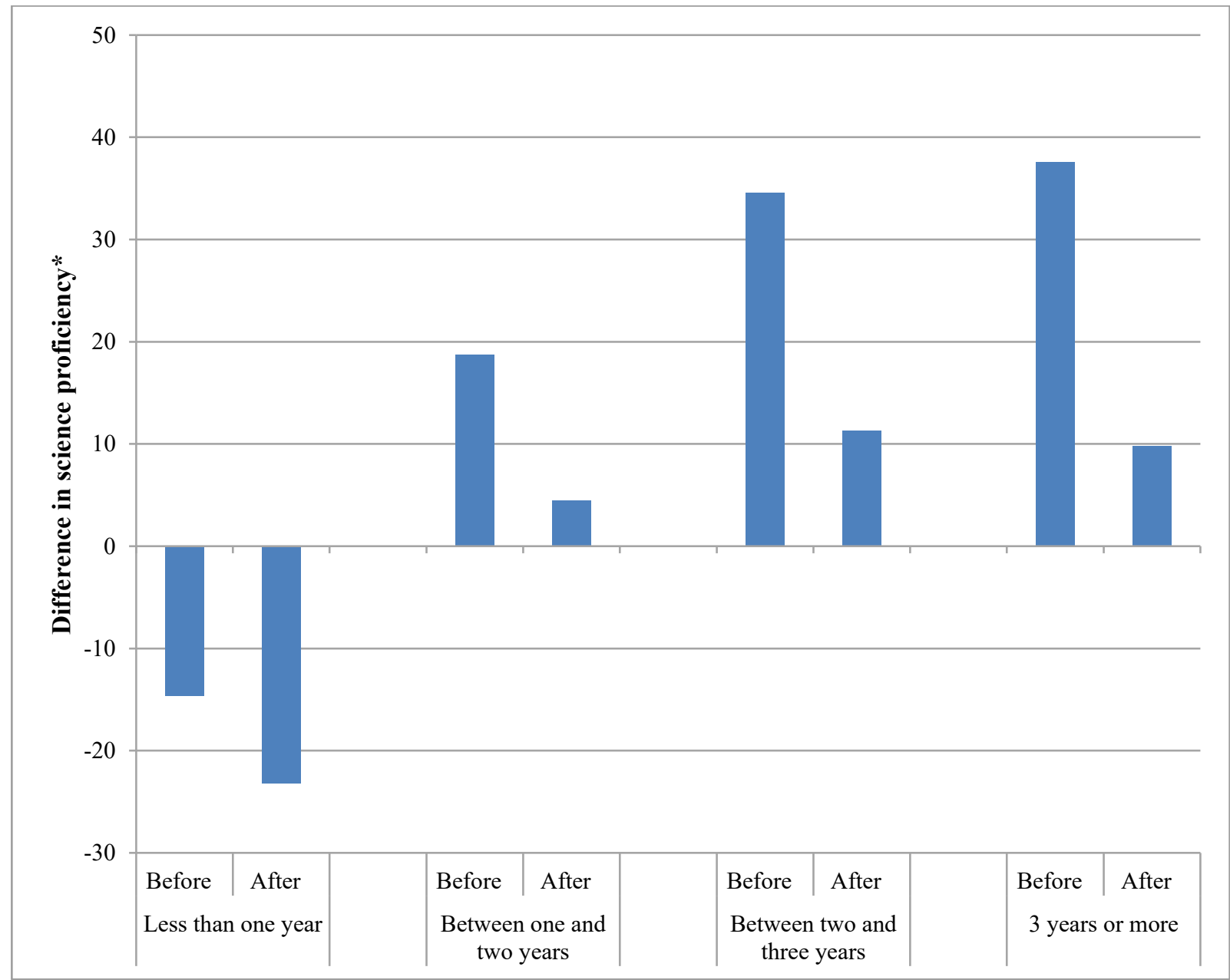

Note: Before and after accounting for PISA's school's and student's socio-economic status.

*Differences in comparison with students that did not attend ECEC.

Source: (OECD, 2015[20]), PISA 2015 Database (accessed 15 November 2019).

Another illustration of the fact that ECEC programmes does not seem to be fulfilling their objective of improving equity among the students is presented in Figure 9 below. It shows that findings from PISA 2015 indicate that the stratification of academic achievement by SES persist regardless of length of exposure to ECEC programmes. In other words, these results indicate that attendance in ECEC does not lead to reduce performance gap in later academic outcomes between advantaged and disadvantaged students. What is more, even the longest duration of ECEC attendance, i.e. students starting as early as ages one or two, does not achieve any perceivable decrease in the performance gap between the two groups of students. The reasons for these performance gaps are not evident in the PISA data, but likely include aspects of home learning environments as well as aspects of the ECEC environments, such as the quality of ECEC programmes, that also vary with families' SES. Differences in the quality of later schooling and community experiences of these young people from different socio-economic backgrounds could also play a role in keeping or intensifying early gaps between these groups. 
Figure 9. Relationship between age starting ECEC and science proficiency, by socio-economic status

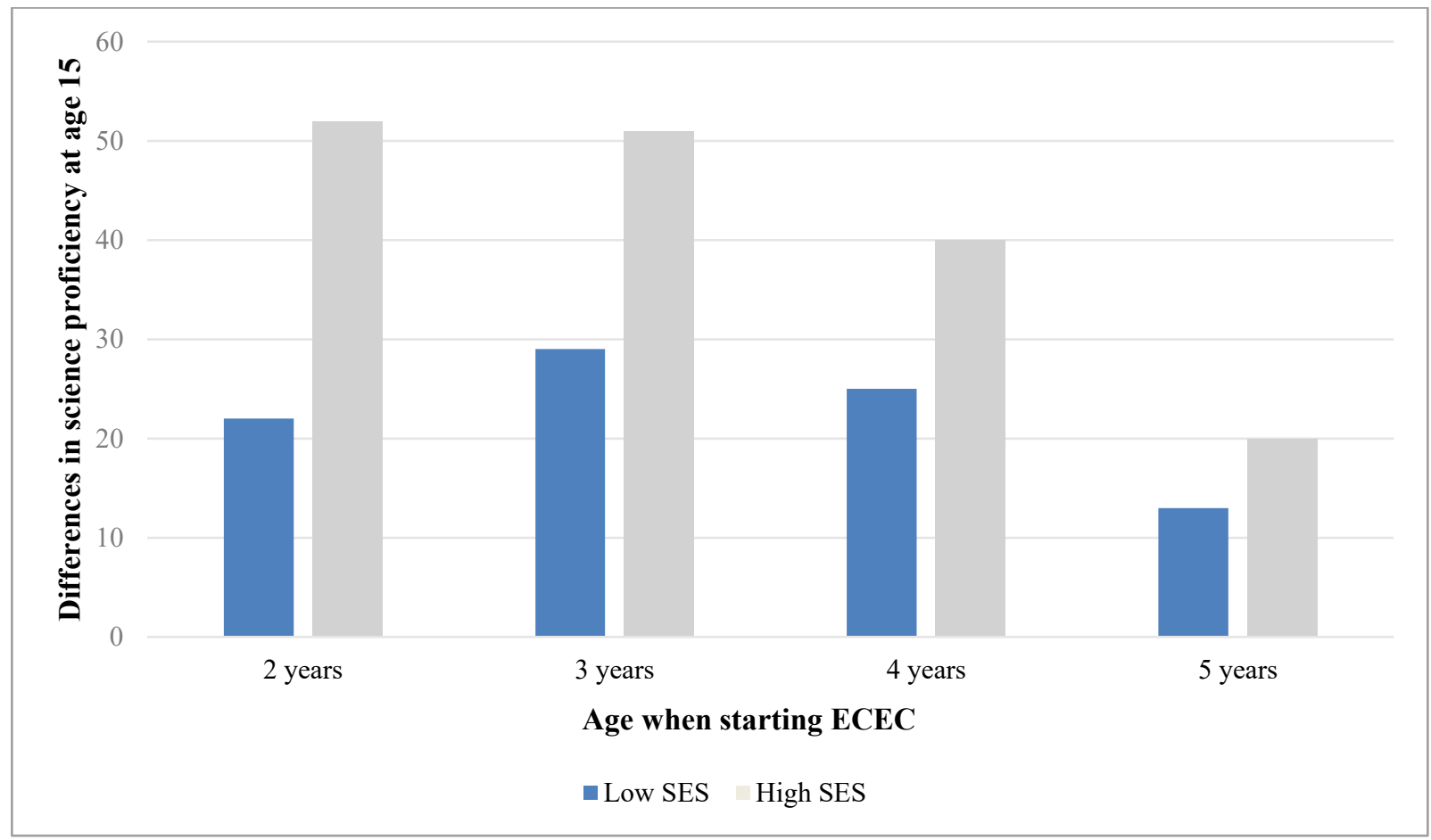

Note: Presented scores represent difference in Science proficiency at age 15 between those that start ECEC at various ages and those that do not attend ECEC, by socio-economic status.

High and low SES represent students in the top and bottom quarter based on their socio-economic profile.

Source: (OECD, 2015[20]), PISA 2015 Database (accessed 15 November 2019).

\section{Quality of ECEC programmes matters}

The results presented so far, as well as the body of research on ECEC effectiveness, indicate that the mere attendance of ECEC programmes on its own is not enough to ensure positive child outcomes (OECD, 2018[38]; Shuey and Kankaraš, 2018 $\left.{ }_{[12]}\right)$. In other words, once a child is present in an ECEC setting, several characteristics of the setting and its provisions determine whether or not the child will benefit from the experience, what kind of benefits will occur, and how long they will persist (OECD, 2015 $[39])$. For example, the British Effective Provision of Pre-School Education (EPPE) Study found short-term effects indicating that pre-school attendance was beneficial for both cognitive and socio-emotional development, especially for children from disadvantaged backgrounds. However, the long-term benefits persisted only for those children that attended high-quality pre-school centres (e.g. (Sammons et al., 2009 ${ }_{[40]}$; Valenti and Tracey, 2016 [41]; Sylva et al., 2011 $1_{[42]}$ ).

One illustration of the importance of providing high quality ECEC programmes is shown in Figure 10. We can see there that the same duration of ECEC attendance, after accounting for students' and schools' socio-economic status, had very different effects across countries. For example, with increased duration of attendance, ECEC programmes have substantial positive effects in Hong Kong (China), Belgium, the United Kingdom and Singapore. On the other hand, students that were attending ECEC programmes in Estonia, Latvia, Poland and, to a lesser degree, the United States, have lower scores in comparison to their compatriots who did not attend these programmes. These different patterns can express different emphases or approaches to the Science in ECEC. 
One of the hypotheses to explain the lower results in Science of those students who reported having attended ECEC in Estonia, Latvia, Poland, and the United States is that emphases could have been placed on other skills such as Math or Language. Thus, differences in Science are not associated in ECEC but rather in other factors such as the quality of primary and secondary education. Another plausible hypothesis is that the effect of attending ECEC in those countries has no significant effects associated with attending ECEC as can be seen in the Figure 7 for Latvia and the United States. The question is then: which kind of characteristics influence or determine the quality of ECEC provision? Some of the aspects that can be included in the category of quality will be included in this report, although undoubtedly 'quality' as a theoretical construct, widely exceeds the purposes of the current report.

\section{Figure 10. Relationship between ECEC attendance and science proficiency across countries}

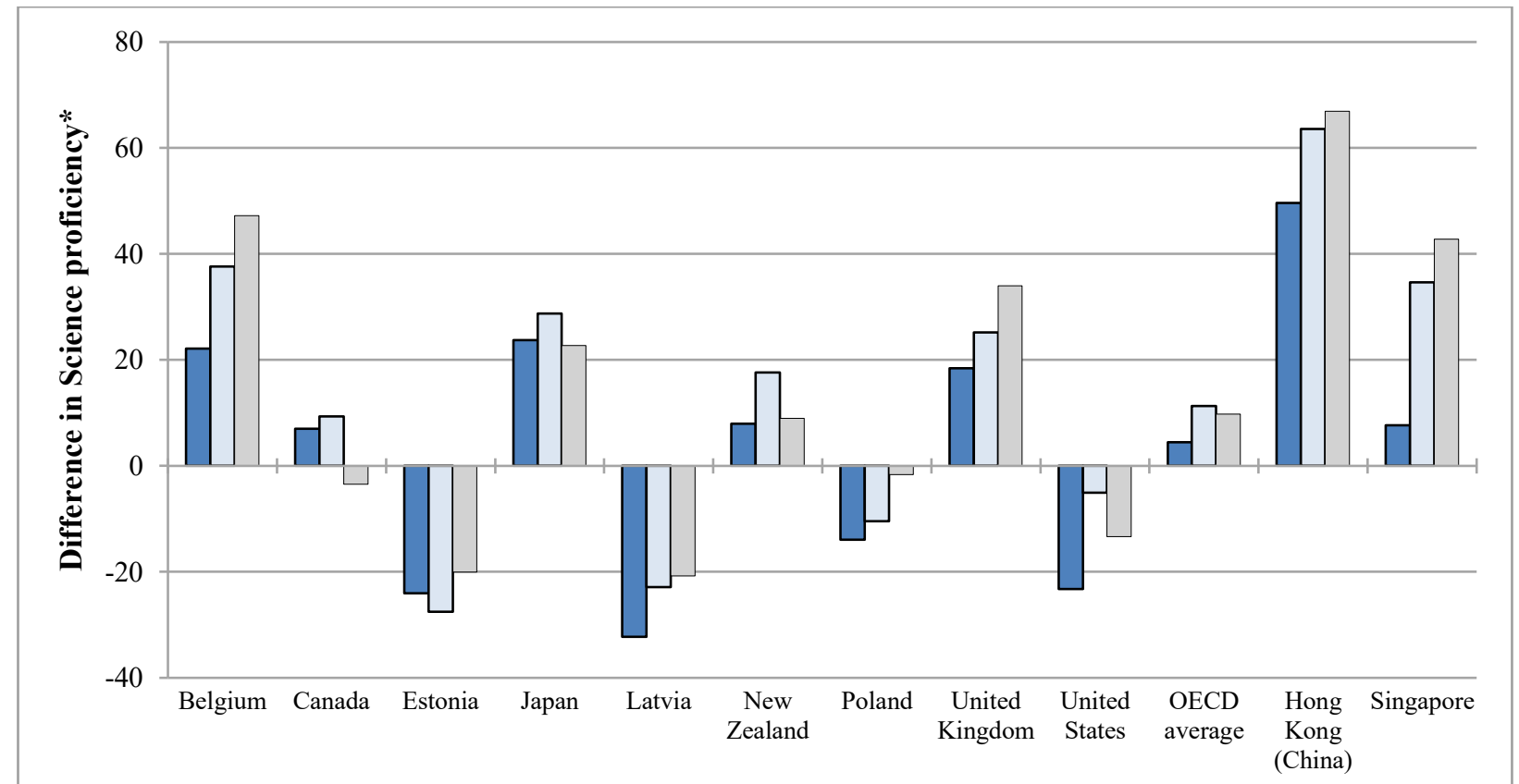

$\square$ Attended ECEC between 1-2 years $\square$ Attended ECEC between 2-3 years $\square$ Attended ECEC for more than 3 years

Note: * Differences in comparison with students that did not attend ECEC.

Source: (OECD, 2015[20]), PISA 2015 Database (accessed 15 November 2019).

\subsection{Staff training}

The qualifications and training of ECEC staff is another often-used indicator of the quality of educational provision. There is a more direct measure of this indicator in PISA 2015, where parents are asked if the supervision of their children in 'supervision and care' programmes was staffed by trained supervisors. Differences in proficiency scores depending on whether or not a trained person conducted supervision are shown in Figure 11. Results show that across OECD countries, students supervised by trained staff scored between 15-20 points higher than those supervised by untrained staff. These differences could also reflect the fact that ECEC centres with trained staff were offering better quality programmes and having better facilities than those with untrained staff. 
Figure 11. Differences in proficiency scores depending on staff training

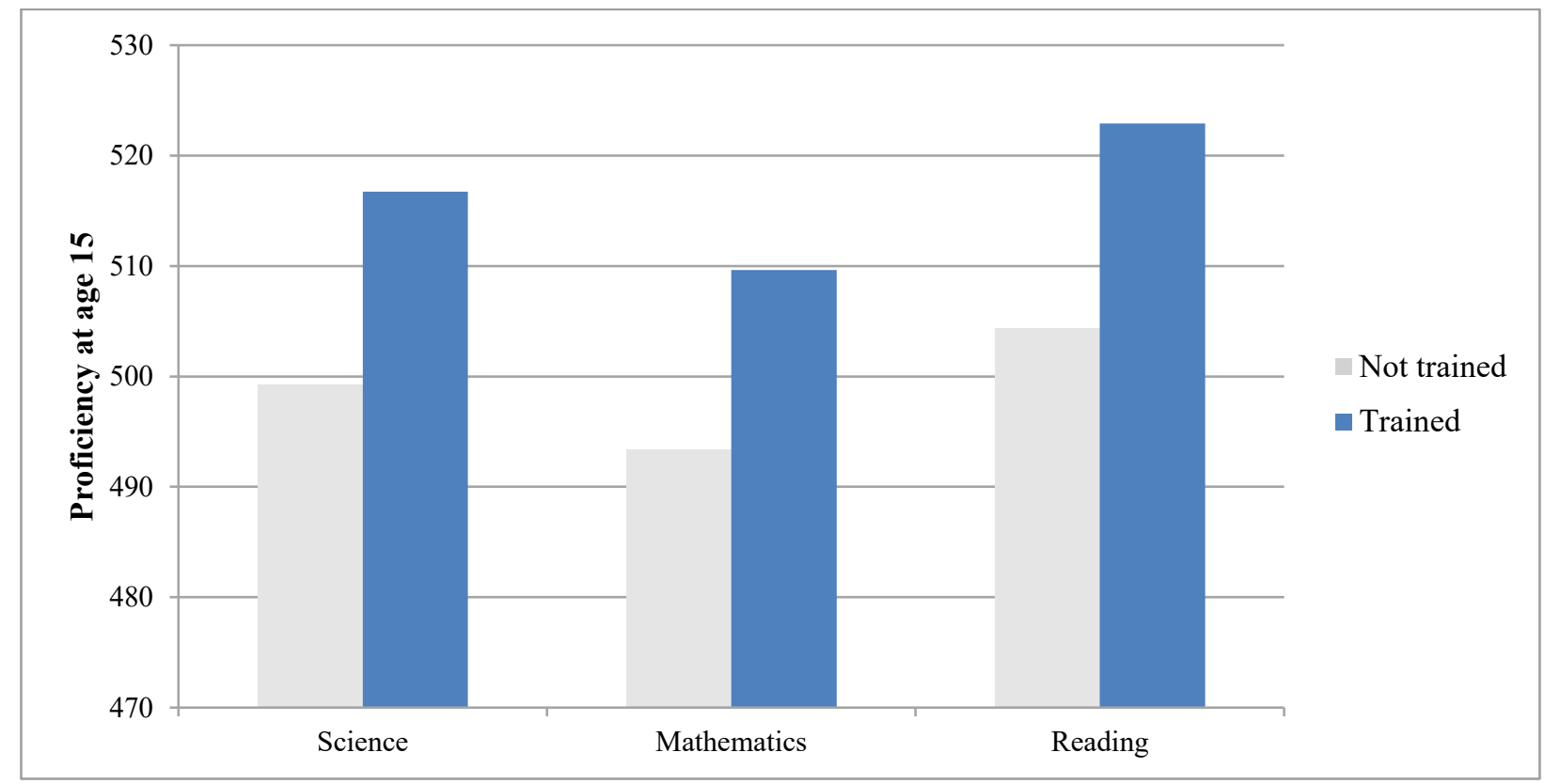

Source: (OECD, 2015[20]), PISA 2015 Database (accessed 15 November 2019).

\subsubsection{Management and funding type}

The type of funding and management could affect the quality of programmes as well (Belfield, 2006 ${ }_{[43]}$ ). There are two sources of funding for ECEC programmes: public and private. In most countries, public institutions more commonly provide ECEC programmes than private ones, especially in the case of kindergartens or ECEC. Public institutions often charge lower fees than private institutions and are therefore of special importance for lowincome families who could not afford to make large private contributions. However, private institutions can also receive public funding and be mostly run by public financing, in which case they provide private management of public funds.

Differences in students' science proficiency depending on the funding and management type of their ECEC institutions are presented in Figure 12. We can see that across OECD countries, students coming from privately managed pre-schools have substantially higher scores than those coming from publicly run institutions. The funding source does not seem to have much influence, as long as the institution is managed by a private provider. These results may reflect the fact that private management may allow for a more flexible and efficient ECEC system. In addition, it may reflect the fact that children from advantaged backgrounds are more likely to enrol in private schools. On the other hand, poorer results of students from publicly run systems may be due to their more uniform quality of provision since these programmes are more highly regulated and may be less responsive to differing demands of their users. However, these results may also reflect differences in the socioeconomic background of students who attend publicly and privately run providers. 
Figure 12. Differences in students' science proficiency and type of funding of their early childhood education and care (ECEC) institutions

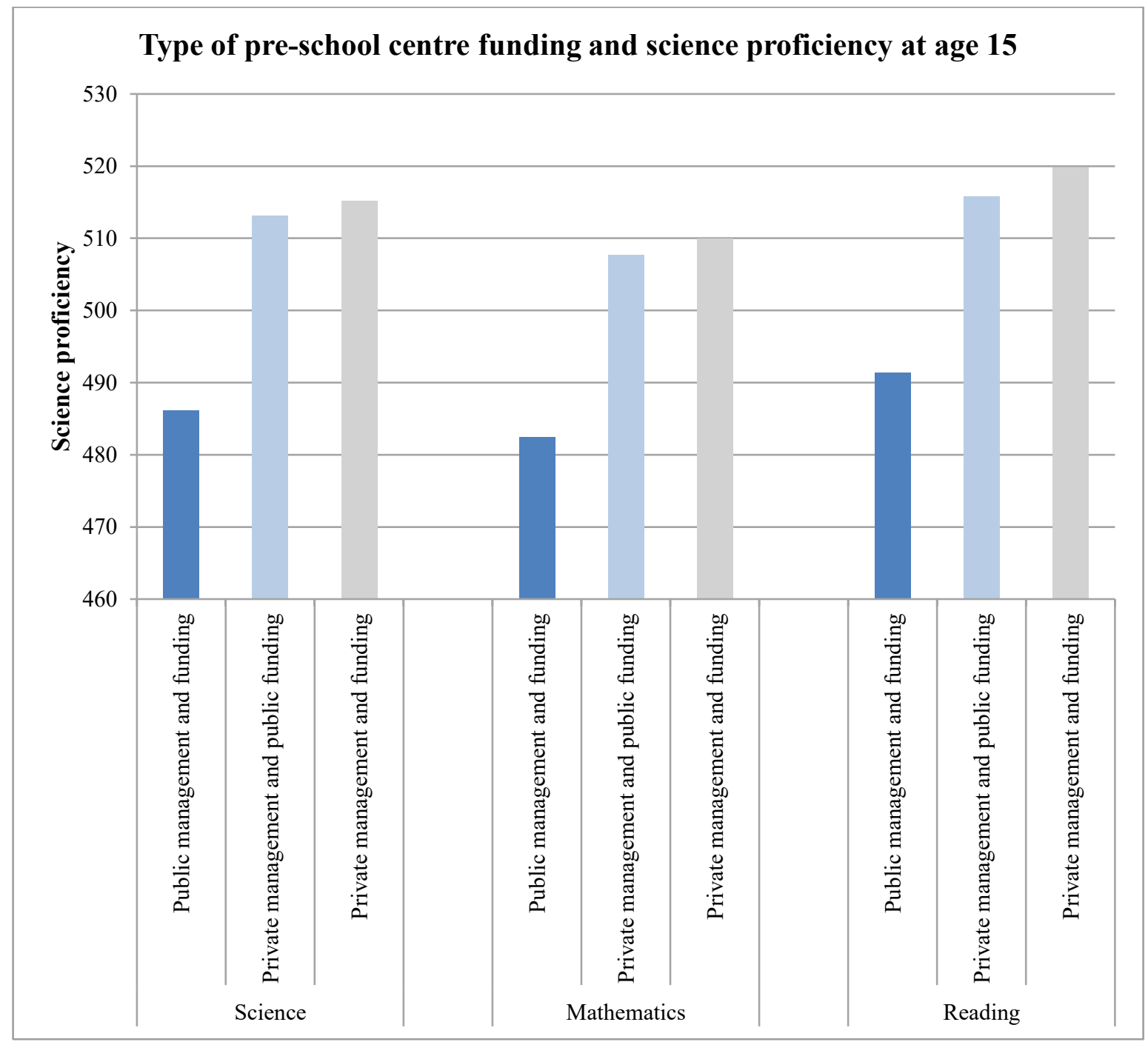

Source: (OECD, 2015[20]), PISA 2015 Database (accessed 15 November 2019).

\subsubsection{Differences across students' school characteristics}

Another set of students' background variable concerns the socio-economic characteristics of the schools that students attend. Figure 13 shows differences in the average duration of ECEC attendance across different types of schools in which students are currently enrolled. Across OECD countries, students in socio-economically advantaged schools had attended about four months more ECEC school than students in disadvantaged schools. Across OECD countries, students in urban schools had spent two months more in pre-primary school than students in rural schools, and students in private schools had spent two months more in pre-primary education than students in public schools. These results point out that those students from advantaged backgrounds are more likely to spend more time in ECEC settings, and thus benefit more from their ECEC experience than less advantaged children. 
Figure 13. Differences in duration of ECEC attendance, by school's characteristics

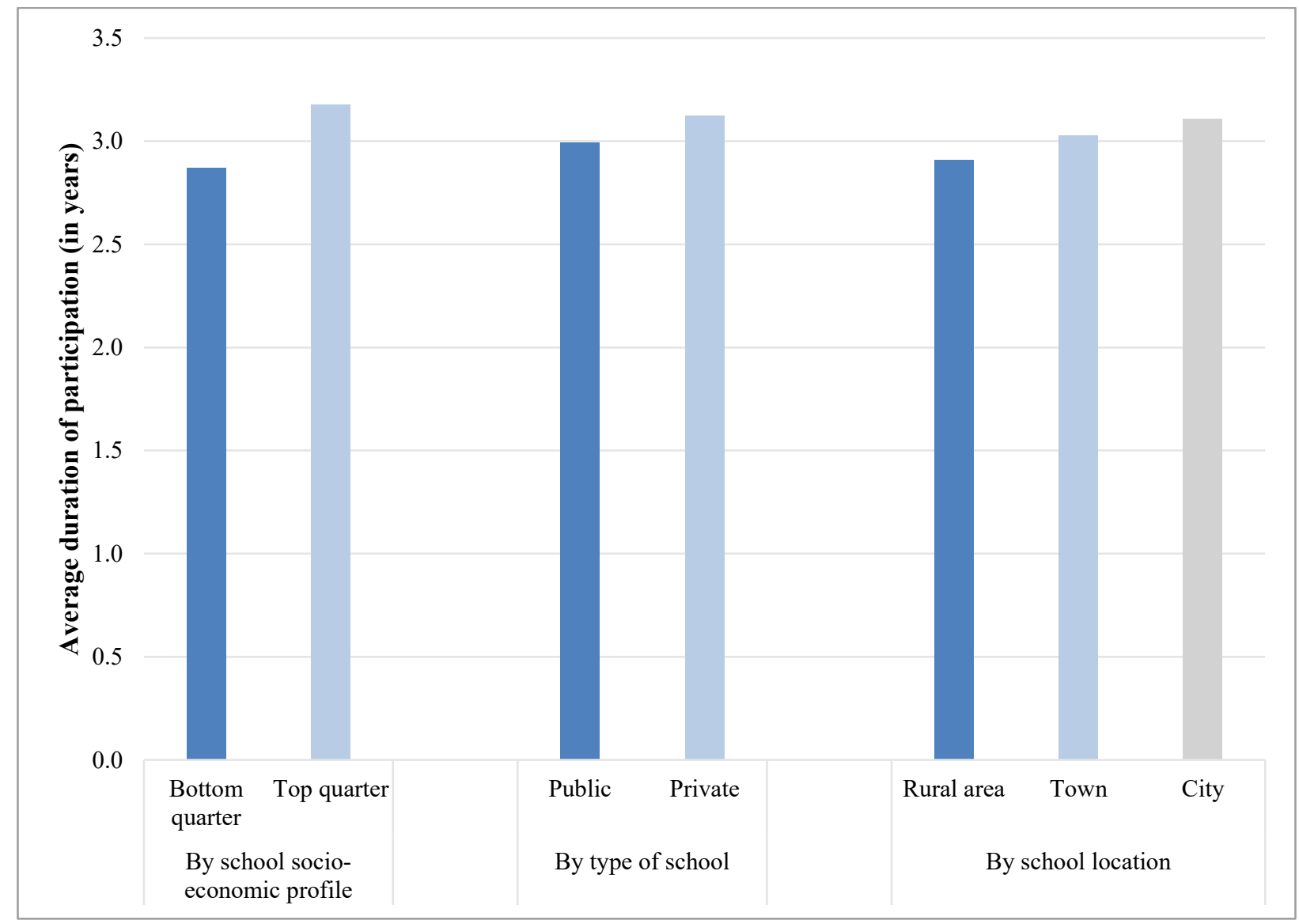

Source: (OECD, 2015[20]), PISA 2015 Database (accessed 15 November 2019).

\subsubsection{Intensity of ECEC programmes}

Apart from the typical age of entry, it could be expected that the daily and weekly intensity of these programmes may also play a role in explaining the differences in PISA outcomes. A certain degree of intensity may be necessary for programmes to have beneficial effects, especially relatively long-term effects such as those measured in PISA (Logan J et al., $2011_{[44]}$; Sylva et al., 2011 $1_{[42]}$ ). Across OECD countries, the relationship between the intensity of weekly attendance and later students' proficiency is curvilinear, indicating an optimal range of attendance spanning between 20-40 hours per week (Figure 15). Slightly more or less intense programmes (i.e. those in range of 40-50 hours and 10-20 hours per week) are somewhat less beneficial. However, the real difference is present in the case of a very short (less than 10 hours) and very long (more than 50 hours) programmes, with students who attended these programmes having substantially lower proficiency scores than students who attended greater or fewer hours respectively. Different reasons may be behind the differences in two extremes. On the one hand, students with few hours of weekly provision are probably not having enough exposure for the programme to have positive effects. On the other hand, those students with more than 50 hours of weekly attendance may have too little contact with family and their ECEC environment may have less of educational and more of a day-care character. 
Figure 14. Relationship between intensity of ECEC attendance and proficiency at age 15

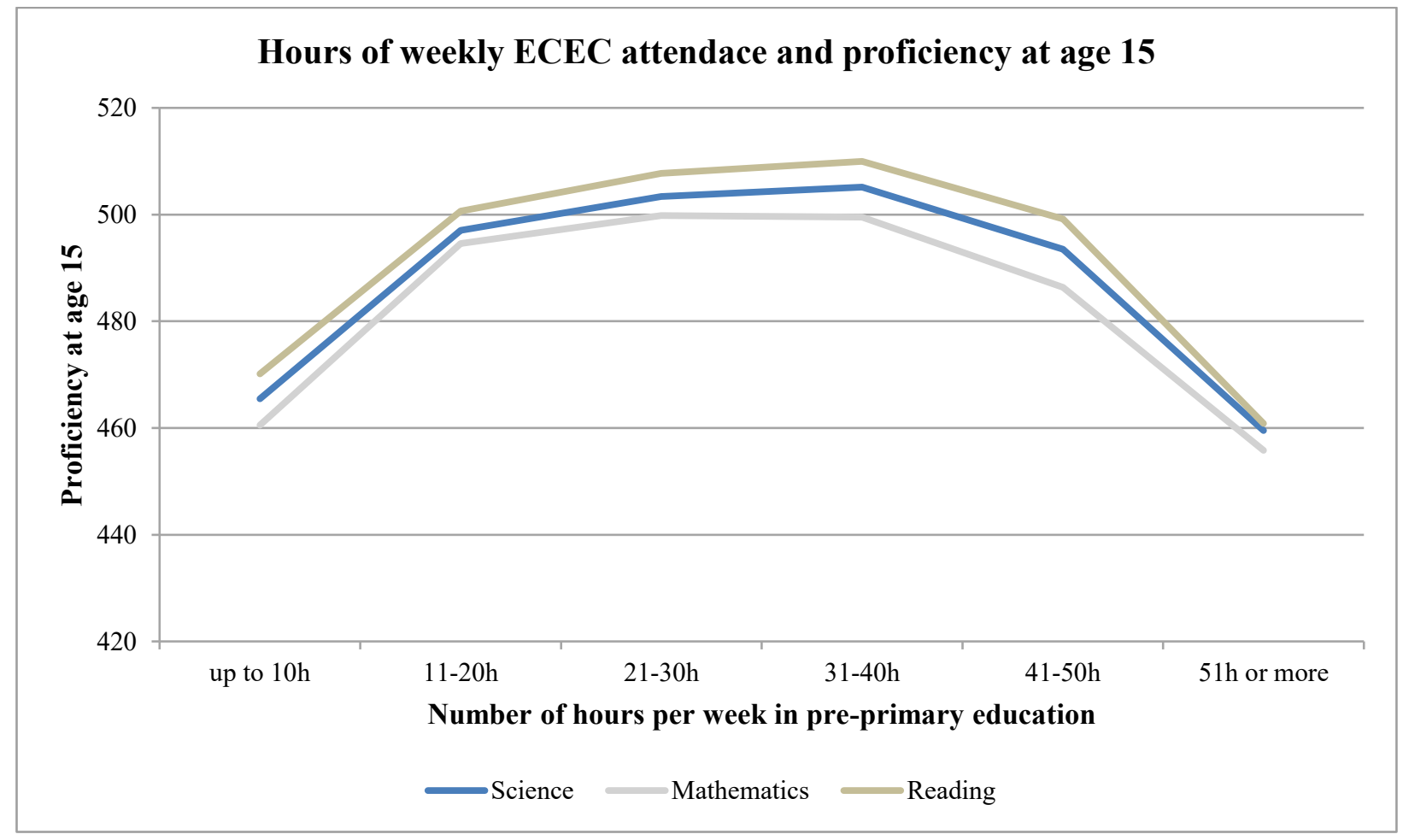

Source: (OECD, 2015[20]), PISA 2015 Database (accessed 15 November 2019).

\subsubsection{Parents' reasons for enrolling their children in ECEC}

The results presented so far show the type, duration and intensity of students' ECEC experience. However, it is interesting also to know parents' reasons for enrolling their children in different types of ECEC programmes. In PISA 2015, parents choose from four reasons for enrolling their children in each of the three types of ECEC settings. Their answers are presented in Figure 15. As could be expected, across OECD countries, students who were attending ECEC programmes only because it was a mandatory obligation for their parents have the lowest scores. This may reflect the fact that in these cases parents were not choosing programmes with a stronger learning focus, or that the quality of programmes where attendance was mandatory was lower. Similarly, sending children to ECEC programmes only because other children attend them also implies that parents are not focusing on the educational dimension of ECEC experiences and that the quality of these programmes may not be the best. 
Figure 15. Parental reason for child's attendance of different types of early childhood education and care (ECEC) programmes and students' science proficiency

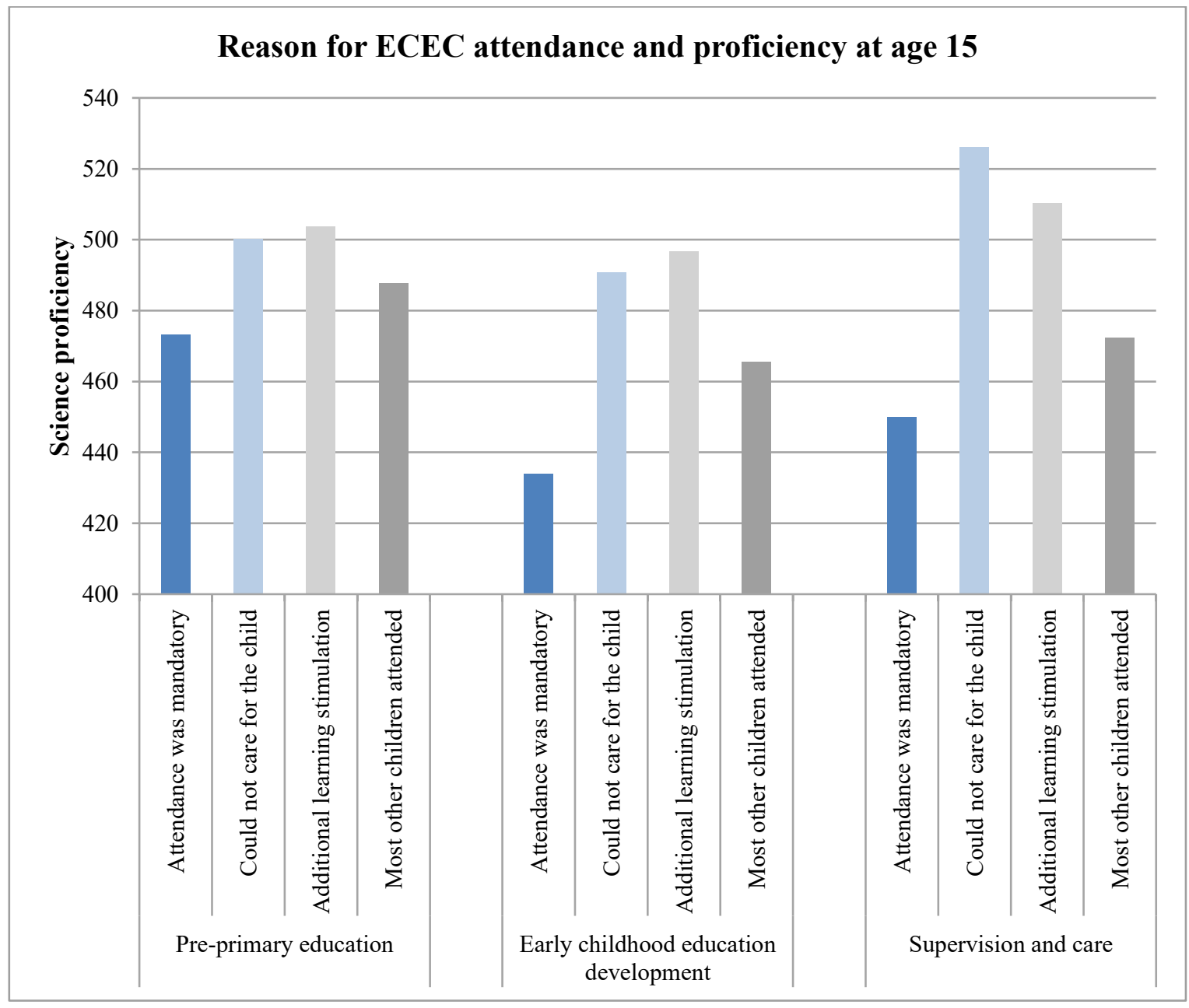

Source: (OECD, 2015[20]), PISA 2015 Database (accessed 15 November 2019).

Additional learning stimulation, as expected, is the most beneficial motivation of parents in pre-school and ECEC programmes. Likewise, in all three ECEC types, but especially in the supervision and care programmes, ECEC programmes are very beneficial in those situations where parents are not able to provide necessary care themselves all the time (e.g. when both parents are working). This finding illustrates how important ECEC programmes are in terms of providing a stimulating learning environment in situations when this may be lacking. In this way, apart from their educational role, they fulfil their economic and wider social role of allowing both parents to be economically and socially active, thus improving employment rates and reducing gender inequalities.

\section{Conclusions}

PISA results show that, across the OECD countries, students who had attended ECEC tend to have higher scores in academic proficiencies at age 15 than students who had not attended ECEC programmes (or those that had attended for less than one year). The results also show that entering ECEC programmes earlier than this time is associated with lower proficiencies at age 15, which might indicate that the quality of provision in ECEC 
programmes for these atypically early ages (in most countries these are ages $0-2$ ) is not necessarily optimal. The ECEC quality is a factor that undoubtedly can affect later academic outcomes and it has not been included in this report owing to the limitations of the database in this regard. Additionally, it is also possible that children at such early ages are better off at their homes, where their parents and caregivers can provide them better care and opportunities for development.

However, these generally positive results are coupled with troubling findings. The differences in academic proficiencies between students that attended ECEC and those that did not are almost annulled when students' SES is taken into account. In other words, ECEC programmes were apparently not able to mitigate influence of existing inequalities and improve equity among students. Moreover, apart from disadvantaged students not being able to catch up with students from advantageous backgrounds through their attendance in ECEC programmes, they are also disadvantaged in their opportunities to attend ECEC in the first place. In particular, a larger proportion of children from low SES are not attending ECEC compared to their peers, or when they attend they start later than their peers from high SES, affecting the critical learning opportunities that can be acquired during those years.

Thus, while attending ECEC is related to the student's SES, which in turn seems to explain later academic proficiencies, these results should be considered with caution and it should not be assumed that SES is the explanation for outcomes. For example, ECEC quality, ECEC centres' features, and teacher experience are among other factors which are equally distributed among the countries, and in different SES groups. Attending ECEC has to be considered as the first step in a series of progressions and developments in primary and secondary education, which have to be considered as a function within the student's SES.

While attending ECEC represents an opportunity to acquire skills and knowledge in the critical years, association of ECEC participation and later academic achievement varies considerably across PISA countries. Such results clearly illustrate that attendance alone is not enough to explain the dispersion in PISA results. Country-specific policy context and quality of their ECEC provision are other critical factors that will ultimately be a deciding factor on whether they will provide beneficial effects. Results from some of the countries can be seen as generally encouraging empirical evidence about the possibility of positive influences of ECEC programmes. However, in other cases, they can also be a warning that for these programmes to deliver their potential benefits, a strong emphasis on their high quality and wide outreach need to be a policy priority.

Indeed, analysis of various quality indicators does point out that improved quality of ECEC programmes is associated with higher academic skills at later stage. Students attending programmes with the following characteristics were consistently having higher academic proficiencies than students attending different types of ECEC programmes: trained staff; a smaller number of children per staff; funded privately; settled in urban environments; and better school/centre SES.

In addition to the attendance and the quality, the intensity of the ECEC programmes is another important aspect of the overall ECEC provision. Although the great majority of students are now at some point participating in ECEC programmes, many of them have done so for a short duration (i.e. for less than two years) and with low intensity (i.e. with fewer than 10 hours per week). PISA findings provide a clear indication that both longer duration and greater intensity tend to be associated with higher academic proficiencies at a later age. However, they also show that, like in the case with duration of attendance, there is an optimum level of ECEC experience and that too much intensity (more than 40 hours per week) may not provide an optimal balance between exposure to home care and learning environment and additional educational stimulation provided in ECEC programmes. 
Presented PISA data on students' ECEC experiences, although valuable, are limited in scope and have important methodological constrains. PISA 2015 results refer to ECEC settings that existed some 10-15 years ago, when these students were attending these programmes. This situation may have changed quite substantially in the meantime and these changes could not be reflected in these findings. Results were also based on the premise that student and parent reports on students ECEC experiences are accurate and reliable, which is not always the case when one is asked to report on events that happened some ten years ago. Moreover, although PISA 2015 included several questions on students' ECEC participation to both parent and student questionnaires, there are still many relevant aspects of this topic that are not present in PISA data. Finally, it is important to bear in mind that PISA data are of cross-sectional nature, and thus offer only correlational type of analyses. This limitation is especially important in the context of possible causal influences between students' ECEC experiences and their academic proficiencies some ten years later since myriad of other factors could confound this relationship over such an extended period. These constraints, taken together, do not allow for a more comprehensive analysis of children's learning outcomes in relation with their ECEC experiences using PISA 2015 data.

However, findings from PISA studies do offer valuable indicators of possible relations (or absence of them) between various aspects of quantity and quality of ECEC provision and later academic achievement. They highlight the fact that mere attendance is not enough, and that the emphasis of policy makers should be placed on both expanding coverage and intensity of these programmes but also making sure that the quality of their provision, especially regarding their educational component, is achieved. In this sense, presented findings form PISA 2015 could be a call for further studies that would provide answers for questions opened by these results. The OECD's International Early Learning and Childwellbeing Study is one such research project that would attempt to offer much more timely and comprehensive information on the relationship between children's learning environments, their individual characteristics, and their learning outcomes. In doing so, it will allow for better examination of factors that foster and hinder learning within ECEC environment and how these factors differ across children from coming from different social and cultural backgrounds. Policy makers could then use this information to set up more effective ECEC programmes, which would be of better value to participating children, especially those from disadvantaged groups. 


\section{References}

Aikens, N. and O. Barbarin (2008), "Socioeconomic differences in reading trajectories: The contribution of family, neighborhood, and school contexts", Journal of Educational

Psychology, Vol. 100/2, pp. 235-251, http://dx.doi.org/10.1037/0022-0663.100.2.235.

Arnold, D. and G. Doctoroff (2003), "The early education of socioeconomically disadvantaged children”, Annual Review of Psychology, Vol. 54, pp. 517-545,

http://dx.doi.org/10.1146/annurev.psych.54.111301.145442.

Barnett, W. (2001), "Preschool education for economically disadvantaged children: Effects on reading achievement and related outcomes", in Neuman, S. and D. Dickinson (eds.), Handbook of early literacy research, Guilford Press, New York, NY.

Belfield, C. (2006), Financing early childhood care and education: an international review. Education for All Global Monitoring Report 2007: Strong Foundations, Early Childhood Education and Care.

Berlinski, S., S. Galiani and P. Gertler (2009), "The effect of pre-primary education on primary school, performance", Journal of Public Economics, Vol. 93/1, pp. 219-234, http://dx.doi.org/10.1016jpubeco.2008.09.002.

Bradley, R. et al. (2001), "The home environments of children in the United States Part II: Relations with behavioral development through age thirteen", Child Development, Vol. 72/6, pp. 1868-1886.

Brooks-Gunn, J. and G. Duncan (7), “The effects of poverty on children”, Future Child, Vol. 2, pp. 55-71.

Buckingham, J., R. Beaman and K. Wheldall (2013), "Why poor children are more likely to become poor readers: the early years”, Educational Review, Vol. 664, pp. 428-446, http://dx.doi.org/doi: 10.1080/00131911.2013.795129.

Duncan, G. and K. Magnuson (2013), "Investing in Preschool Programs”, Journal of Economic Perspectives, Vol. 27/2, pp. 109-131.

Entwisle, D., K. Alexander and L. Olson (1997), Children, Schools and Inequality, Westview Press.

Fernald, A., V. Marchman and A. Weisleder (2013), "SES differences in language processing skill and vocabulary are evident at 18 months", Developmental Science, Vol. 16/2, pp. 234-248, http://dx.doi.org/10.1111/desc.12019.

Fuller, B. et al. (2017), "Do academic preschools yield stronger benefits? Cognitive emphasis, dosage, and early learning”, Journal of Applied Developmental Psychology, Vol. 52, pp. 1-11.

Hamilton, L. et al. (2016), "The Home Literacy Environment as a Predictor of the Early Literacy Development of Children at Family-Risk of Dyslexia”, Scientific Studies of Reading, Vol. 20/5, pp. 401-419, http://dx.doi.org/10.1080/10888438.2016.1213266.

Heckman, J. (2006), "Skill formation and the economics of investing in disadvantaged children", Science, Vol. 312/5782, pp. 1900-1902. 
Kankaraš, M. (2017), “Personality matters: Relevance and assessment of personality characteristics”, No. 157, OECD Publishing, Paris, http://dx.doi.org/10.1787/8a294376-en.

Logan J, S. et al. (2011), “Children's attendance rates and quality of teacher-child interactions in at-risk preschool classrooms: Contribution to children's expressive language growth”, Child and Youth Care Forum, Vol. 40/6, pp. 457-477.

Mistry, R. et al. (2010), "Family and social risk, and parental investments during the early childhood years as predictors of low-income children's school readiness outcomes", Early Childhood Research Quarterly, Vol. 25/4, pp. 432-449, http://dx.doi.org/10.1016/j.ecresq.2010.01.002.

NICHD Early Child Care Research Network (2006), "Child-care effect sizes for the NICHD Study [36] of Early Child Care and Youth Development”, The American Psychologist, Vol. 61/2, pp. 99116.

NICHD Early Child Care Research Network (2005), “Early child care and children's development in the primary grades: Follow-up results from the NICHD Study of Early Child Care", American Educational Research Journal, Vol. 42/3, pp. 537-570.

NICHD Early Child Care Research Network and G. Duncan (2003), "Modeling the impacts of child care quality on children's preschool cognitive development”, Child Development, Vol. 74/5, pp. 1454-1475.

Noble, K., M. Farah and B. McCandliss (2006), "Socioeconomic background modulates cognition-achievement relationships in reading", Cognitive Development, Vol. 21/3, pp. 349368, http://10.1016/j.cogdev.2006.01.007.

OECD (2017), Starting Strong V: Transitions from Early Childhood Education and Care to Primary Education, Starting Strong, OECD Publishing, Paris, https://dx.doi.org/10.1787/9789264276253-en.

OECD (2015), PISA 2015, OECD Publishing, Paris.

OECD (2015), PISA 2015 Database, https://www.oecd.org/pisa/data/2015database/ (accessed on 15 November 2019).

OECD (2015), Starting Strong IV: Monitoring Quality in Early Childhood Education and Care, OECD Publishing, Paris, http://dx.doi.org/10.1787/9789264233515-en.

OECD (2014), PISA in Focus $n^{\circ} 40$ : Does pre-primary education reach those who need it most?, OECD Publishing, Paris, http://dx.doi.org/10.1787/22260919.

OECD (2013), "How do early childhood education and care (ECEC) policies, systems and quality vary across OECD countries?”, Education Indicators in Focus, Vol. 11, http://dx.doi.org/10.1787/5k49czkz4bq2-en.

OECD (2012), Equity and Quality in Education: Supporting Disadvantaged Students and Schools, OECD Publishing, Paris, http://dx.doi.org/10.1787/9789264130852-en.

OECD (2011), PISA in Focus $n^{\circ}$ : Does participation in pre-primary education translate into better learning outcomes at school?, OECD Publishing, http://dx.doi.org/10.1787/22260919. 
OECD, European Union and UNESCO-UIS (2015), ISCED 2011 operational manual: guidelines for classifying national education programmes and related qualifications, OECD Publishing, Paris, http://dx.doi.org/10.1787/9789264228368-en.

Pungello, E. et al. (2010), "Early educational intervention, early cumulative risk, and early home environment as predictors of young adult outcomes within a high-risk sample", Child Development, Vol. 81, pp. 410-426.

Reynolds, A. et al. (2011), "School-based early childhood education and age-28 well-being: Effects of timing, dosage, and subgroups", Science, Vol. 333, pp. 36-364.

Roberts, J., J. Jurgens and M. Burchina (2005), "The role of home literacy practices in preschool children's language and emergent literacy skills", Journal of Speech, Language, and Hearing Research, Vol. 48/2, pp. 345-359.

Ruhm, C. and J. Waldfogel (2012), "Long-Term Effects of Early Childhood Care and Education", Nordic Economic Policy Review, Vol. 1, pp. 23-51.

Sammons, P. et al. (2009), "Children's cognitive attainment and progress in English primary schools during Key Stage 2: Investigating the potential continuing influences of pre-school education", in Roßbach HG. and Blossfeld HP (eds.), Frühpädagogische Förderung in Institutionen, VS Verlag für Sozialwissenschaften.

Shuey, E. and M. Kankaraš (2018), “The Power and Promise of Early Learning”, OECD Education Working Papers, No. 186, OECD Publishing, Paris, https://doi.org/10.1787/fgb2e53f-en.

Starting Strong (ed.) (2018), Engaging Young Children: Lessons from Research about Quality in Early Childhood Education and Care, OECD Publishing, Paris, https://doi.org/10.1787/9789264085145-en.

Sylva, K. et al. (2011), "Effects of early child-care on cognition, language, and task-related behaviours at 18 months: An English study", British Journal of Developmental Psychology, Vol. 29/1, pp. 18-45.

Temple, J. and A. Reynolds (2007), "Benefits and costs of investments in preschool education: Evidence from the Child-Parent centers and related programs", Economics of Education Review, Vol. 26/1, pp. 126-144.

Valenti, J. and D. Tracey (2016), "Full-day, half-day, and no preschool effects on urban", in PISA 2015, OECD Publishing, Paris.

Weigel, D., S. Martin and K. Bennet (2006), "Mothers' literacy beliefs: Connections with the home literacy environment and pre-school children's literacy development", Journal of Early Childhood Literacy, Vol. 6/2, http://dx.doi.org/10.1177/1468798406066444.

Whitehurst, G. and C. Lonigan (1998), "Child development and emergent literacy", Child Development, Vol. 69, pp. 848-872.

Yoshikawa, H., C. Weiland and J. Brooks-Gunn (2016), "When does preschool matter?", The Future of Children, Vol. 26/2, pp. 21-36.

Yoshikawa, H. et al. (2013), Investing in our future: The evidence base on preschool education, Foundation for Child Development, New York, NY. 


\section{Annex A. Age of entry to early childhood education and care}

Table A A.1. Typical age of entry to early childhood education and care (ECEC) by country and economies according PISA 2015

\begin{tabular}{|c|c|c|c|}
\hline Typical age of entry & Country/Economy & Typical age of entry & Country/Economy \\
\hline 2 & Belgium & 4 & Luxembourg \\
\hline 2 & Iceland & 4 & Singapore \\
\hline 2 & Sweden & 4 & Uruguay \\
\hline 2 & Norway & 4 & Qatar \\
\hline 3 & France & 4 & Greece \\
\hline 3 & Israel & 4 & Australia \\
\hline 3 & Slovak Republic & 4 & United Arab Emirates \\
\hline 3 & Hungary & 4 & Chile \\
\hline 3 & Germany & 4 & Switzerland \\
\hline 3 & B-S-J-G (China) & 4 & Brazil \\
\hline 3 & Czech Republic & 4 & Canada \\
\hline 3 & Austria & 4 & Korea \\
\hline 3 & Spain & 4 & United States \\
\hline 3 & Macao & 5 & Tunisia \\
\hline 3 & Hong Kong & 5 & Chinese Taipei \\
\hline 3 & Portugal & 5 & Dominican Republic \\
\hline 3 & Peru & 5 & Colombia \\
\hline 3 & Italy & 5 & Costa Rica \\
\hline 3 & Spain (Regions) & 5 & Malaysia \\
\hline 3 & Thailand & 5 & Turkey \\
\hline 3 & Japan & & \\
\hline 3 & New Zealand & & \\
\hline 3 & Poland & & \\
\hline 3 & United Kingdom & & \\
\hline 3 & Lithuania & & \\
\hline 3 & Bulgaria & & \\
\hline 3 & Mexico & & \\
\hline 3 & Croatia & & \\
\hline 3 & Denmark & & \\
\hline 3 & Slovenia & & \\
\hline 3 & Ireland & & \\
\hline 3 & Finland & & \\
\hline 3 & Russian Federation & & \\
\hline 3 & Montenegro & & \\
\hline 3 & Estonia & & \\
\hline 3 & Latvia & & \\
\hline
\end{tabular}

Note: B-S-J-G (China) refers to the four PISA-participating Chinese provinces of Beijing, Shanghai, Jiangsu and Guangdong. 
Figure A A.1. Age of entry without considering 'typical age' by country

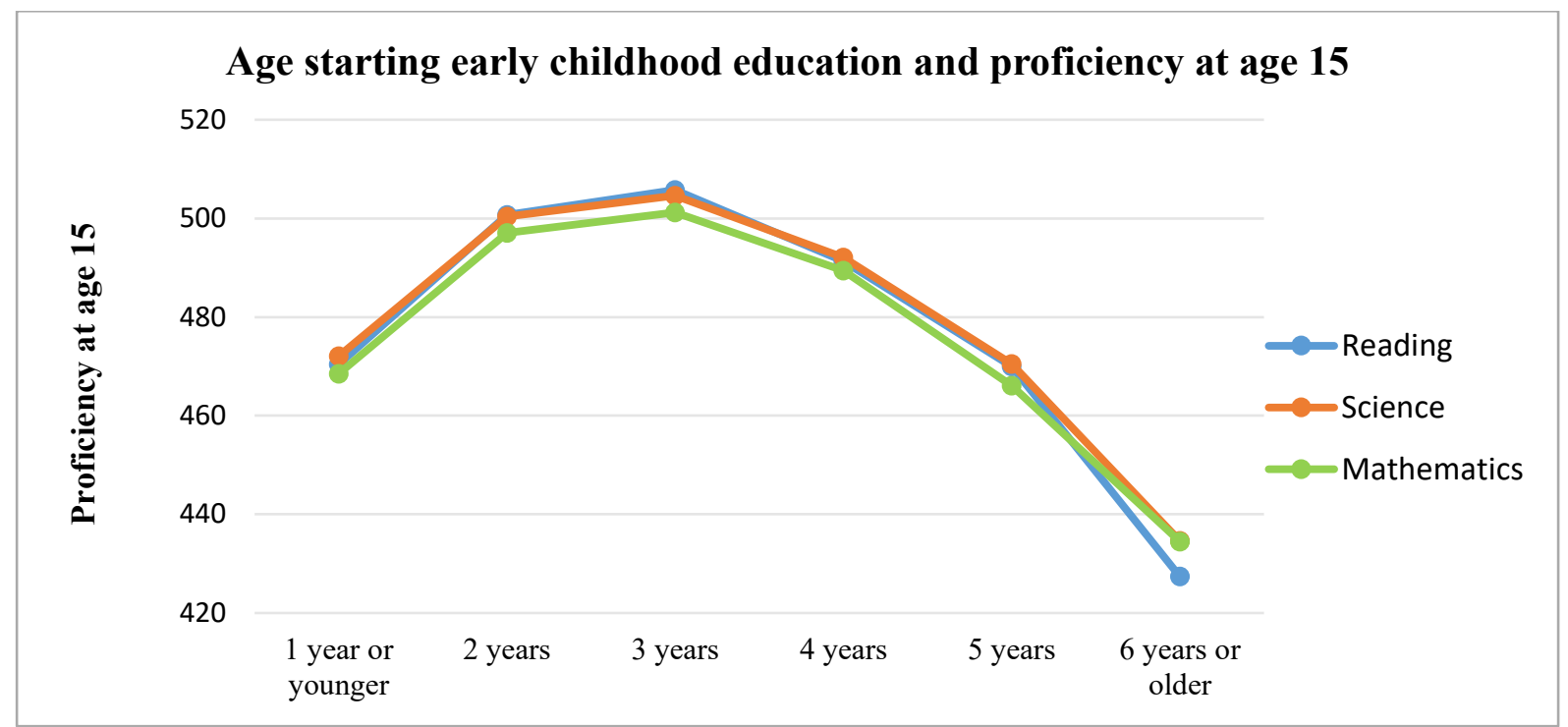

Source: (OECD, 2015[20]), PISA 2015 Database (accessed 15 November 2019).

The graph shows differences in proficiency scores according the age of entry, without considering the typical age of entry at country level. When all countries and economies are considered, it is possible to estimate a negative effect on an early entry of students to ECEC. This effect is not evident when the 'typical age of entry' methodology is used to interpret the results of the impact of the age of entry to ECEC on PISA outcomes. 